\title{
Instructional Package to Promote Early Educators' Use of Behavior-Specific Praise
}

David L Loomis

Follow this and additional works at: https://researchrepository.wvu.edu/etd

\section{Recommended Citation}

Loomis, David L, "Instructional Package to Promote Early Educators' Use of Behavior-Specific Praise" (2018). Graduate Theses, Dissertations, and Problem Reports. 7208.

https://researchrepository.wvu.edu/etd/7208

This Thesis is protected by copyright and/or related rights. It has been brought to you by the The Research Repository @ WVU with permission from the rights-holder(s). You are free to use this Thesis in any way that is permitted by the copyright and related rights legislation that applies to your use. For other uses you must obtain permission from the rights-holder(s) directly, unless additional rights are indicated by a Creative Commons license in the record and/ or on the work itself. This Thesis has been accepted for inclusion in WVU Graduate Theses, Dissertations, and Problem Reports collection by an authorized administrator of The Research Repository @ WVU. For more information, please contact researchrepository@mail.wvu.edu. 


\title{
Instructional Package to Promote Early Educators' Use of Behavior-Specific Praise
}

\author{
David L. Loomis \\ Thesis submitted \\ To the College of Education and Human Services \\ At West Virginia University \\ In partial fulfillment of the requirements for the degree of \\ Master of Arts in \\ Educational Psychology: Program Evaluation and Research \\ Suzanne Hartman, Ph.D., Chair \\ Barbara Gibson Warash, Ph.D. \\ Reagan Curtis, PhD. \\ West Virginia University \\ Department of Learning Sciences and Human Development \\ Morgantown, West Virginia \\ 2018
}

Keywords: behavior-specific praise, self-monitoring, early education, professional development Copyright 2018 David L. Loomis 


\begin{abstract}
Instructional Package to Promote Early Educators' Use of Behavior-

Specific Praise
\end{abstract}

\title{
David L. Loomis
}

Improving quality in early education settings can have multiple short- and long-term benefits for children, families, and the communities those children live and grow up in. Limited access to socioeconomic resources frequently excludes rural and impoverished centers from accessing effective professional development. This study examined the effectiveness of a brief, online-based instructional package that taught early educators how to use self-monitoring to improve their use of behavior-specific praise (BSP), one of the most universally recommended best-practices for teaching (Hester et al., 2009). The instructional package did not require interactions between participants and an expert, thus improving its potential accessibility. A pre-post design was used to determine the effectiveness of the package on improving participants' use of BSP. Surveys were also used to determine participants' rating and endorsement of the training package and their use of self-monitoring and BSP. Multilevel linear modeling (MLM) was used to analyze observational data of participants' use of BSP and demonstrated an average increase from baseline to post-intervention by over $300 \%$. Most but not all participants increased their use of BSP. Participants generally found the instructional package, self-monitoring, and BSP to be acceptable, but some expressed discomfort while using self-monitoring. This study demonstrated an effective way of improving early educators' use of BSP that is inexpensive and easy to disseminate. Future research could examine how to improve participants' discrimination between general and BSP, as well as dissemination of other teaching bestpractices to rural and/or less funded early educators. 
INSTRUCTIONAL PACKAGE TO PROMOTE BEHAVIOR-SPECIFIC PRAISE iii

\section{Acknowledgments}

The author would like to express his sincere and deep appreciation for the many mentors and friends who have influenced his academic progression and nurtured his scientific intellect. Thank you, Sue, for your guidance and for being nothing but supportive and the loudest cheerleader in the room. Thank you, Reagan for modelling excellence in navigating 'rival' schools of thought and the pursuit meaningful research. Thank you, Bobbie for sharing the joys of early education with me. Thank you to my close friends: Dr. Jon Mettrick for guiding me to academe and for your instruction in kata ton orthon logon; Morgan Prunty and Luke Maranto for their many hours of data collection; Tatianna Evanisko for helping create the instructional presentation; and Amy for being the best. 
INSTRUCTIONAL PACKAGE TO PROMOTE BEHAVIOR-SPECIFIC PRAISE iv

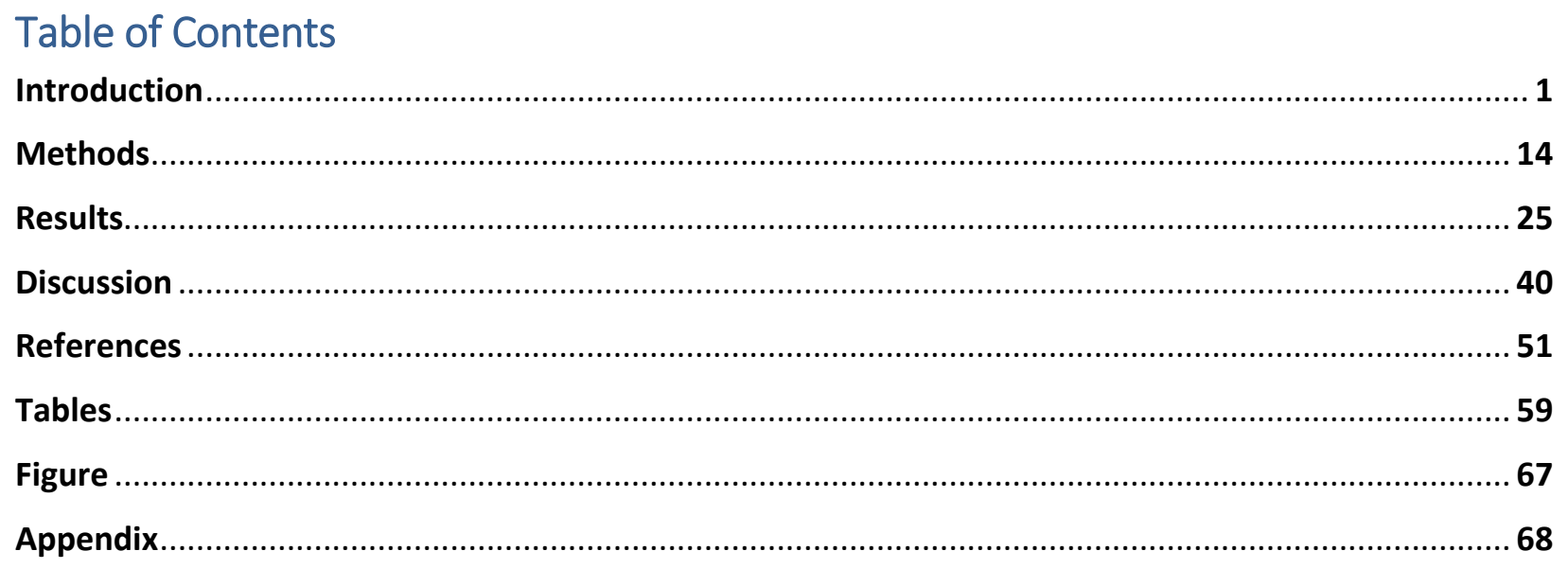


INSTRUCTIONAL PACKAGE TO PROMOTE BEHAVIOR-SPECIFIC PRAISE 1

Instructional Package to Promote Early Educators' Use of Behavior-Specific Praise

\section{Introduction}

Proper development during early childhood is understood by educators, psychologists, and health professionals as creating the foundation for healthy and successful development into childhood, adolescence, and beyond. High quality early education has been shown to have broad positive effects on short- and long-term development. Some short-term benefits of high quality early education include higher academic performance, better social skills, fewer grade retentions, and fewer referrals for special education services (Barnett, 2008; Isaacs, 2008; Jennings \& Diprete, 2010). Long-term benefits include higher rates of high school graduation, fewer teen pregnancies, and reduced criminal behavior during adolescence and beyond (Barnett, 2008; Isaacs, 2008). Although high-quality educative environments have been shown to produce positive outcomes, low-quality environments have been shown to produce negative outcomes, such as slowed academic gains and fewer literacy skills (Mashburn, 2008). It is essential for early education researchers and practitioners to identify and utilize methods to provide highquality learning environments for young children.

Researchers and practitioners interested in improving the quality of early childhood learning environments can focus on many areas. Myers (2004) provides an international review of measurements and statements regarding the quality of early childhood care and identified five general domains of quality: available physical and human resources; educational management (organization and administration); educational process; relationships with families and communities; and health, safety, and hygiene. A more simplified understanding of early childhood care and education quality distinguishes between two domains: structural quality and process quality (NIHCD, 2002). Structural quality, which is thought to have an indirect impact 


\section{INSTRUCTIONAL PACKAGE TO PROMOTE BEHAVIOR-SPECIFIC PRAISE 2}

on child outcomes by supporting or facilitating high process quality, includes staff education levels, elements of safety related to the physical classroom environment, access to resources, and low child-to-staff ratios within the educational environment (Ishimine \& Tayler, 2014). Process quality, which is thought to have a direct impact on child outcomes, includes all the day-to-day interactions between teachers and students (which overlaps with the educational management and educational processes identified by Myers, 2004), and is frequently improved through effective staff training or professional development activities (NICHD, 2002). By providing staff with the necessary knowledge and skills, they can create nurturing environments which help maximize the development of their learners. Non-degree seeking professional development activities can vary widely in nature from afternoon workshops to multi-day events, typically led by expert coaches delivering the content (Labone \& Long, 2014). One method of professional development takes the form of an instructional "package" in which educators are given manualized content that contains a set of instructions and information aimed at improving educators' quality of instruction. One example of such a professional development training package is the PAX Good Behavior Game, which guides teachers to use rule setting, positive reinforcement, planned ignoring, consensus building, and group contingencies in a cohesive manner (Embry, Staatmeier, Richardson, Lauger, \& Mitich, 2003). Training packages can focus on multiple aspects of the instructional environment, as does the PAX Good Behavior Game, or they can focus on single elements of instruction, such as increasing teachers' use of behaviorspecific praise (BSP; Cavanaugh, 2013).

Although packages of teaching strategies have demonstrated remarkable benefits for students, they often require a heavy investment of time and resources, which can limit their rates of adoption. Embry and Biglan (2008) recommend researchers and practitioners focus on 


\section{INSTRUCTIONAL PACKAGE TO PROMOTE BEHAVIOR-SPECIFIC PRAISE 3}

evidenced-base kernels, which they define as "fundamental units of behavioral influence that appear to underlie effective prevention and treatment for children, adults, and families" (p. 75). By focusing on just one evidence-based kernel, rather than an entire package, professional development practices may be streamlined, thereby reducing the time and cost of training. Behavior-specific praise, defined as the delivery of praise that also identifies the behavior being praised, is one evidence-based kernel that has been identified as a necessary component for over 20 empirically-supported teaching packages (McLeod, Sutherland, Martinez, Conroy, Snyder, \& Southam-Gerow, 2016). In addition to its packaged use, decades of research have shown that BSP by itself is a powerful teaching tool to help create a positive and nurturing learning environment, teach learners new skills, and reduce the occurrence of disruptive behaviors (Hancock, 2002, Hester, Hendrickson, \& Gable, 2009; Sutherland, Copeland, \& Wehby, 2001). Previous research has demonstrated that the most effective form of professional development involves the use of feedback, where teachers' use of a target strategy (e.g. praise) is tracked and communicated to the teacher (Cavanaugh, 2013). Professional development activities that do not include the use of feedback tend to either have no effect on teaching practices, or are so minimal that they are clinically irrelevant (Ward-Horner \& Sturmey, 2012; Cavanaugh, 2013). Feedback has most commonly taken the form of in-person coaching. Although effective, such coaching is limiting for three reasons: first, the extended time it takes to meet with coaches can be burdensome on an already overworked teaching population. Second, the cost of hiring a coach can be disproportionately burdensome to early education centers that serve children from low socioeconomic status families. And third, coaches are not always available in rural areas (Connell, Sanders, \& Markie-Dadds, 1997; NICHD, 2002; St. Peter, et al., 2014). 


\section{INSTRUCTIONAL PACKAGE TO PROMOTE BEHAVIOR-SPECIFIC PRAISE 4}

Some studies have worked around the drawbacks inherent in the use of coach-provided feedback by teaching educators to use self-monitoring practices in which the educator tracks their own use of a teaching behavior and self-assesses their use in comparison to a preestablished goal (Simonsen, MacSuga, Fallon, \& Sugai, 2013). The current study aims to improve the accessibility of high-quality professional development through the use of an instructional package that helps teachers learn how to effectively use BSP and how to use selfmonitoring to ensure high fidelity of BSP implementation. This study builds on the work done by Kalis, Vannest, and Parker (2007) who demonstrated self-monitoring to be an effective professional development strategy for improving the use of BSP, and Simonsen and colleagues (2013) who compared multiple self-monitoring strategies and their effectiveness of increasing teachers' use of BSPs. This study aims to extend these prior works in two ways. First, by improving the external generalizability of the results by using a within-subjects group design and by not prompting participants to use BSP during observations, and second, by increasing the adoptability of the professional development package by making it available online, potentially accessible to anyone with an internet connection.

\section{Nurturing Environments and Process Quality}

Nurturing environments are essential for maximizing young children's development. Safe spaces characterized by regular, predictable, and frequently positive interactions with adults and peers are considered the best type of environment for young children to learn and grow (Biglan, 2015). The idealized task of caretakers in all roles - teacher, parent, babysitter, older sibling - is to create nurturing environments for the young. The idealized task of researchers in all fields affecting early child development - pediatricians, developmental psychologists, early childhood educators - is to find ways to help caretakers create nurturing environments for the young. As 


\section{INSTRUCTIONAL PACKAGE TO PROMOTE BEHAVIOR-SPECIFIC PRAISE 5}

mentioned previously, nurturing environments may be characterized primarily by their physical attributes (structural quality; e.g., safe spaces are more likely to be nurturing than unsafe spaces), or by their relationship attributes (process quality; e.g., a teacher who provides consistent expectations and rich schedules of reinforcement for appropriate behavior is more likely to create a nurturing environment than a teacher that provides inconsistent expectations and rarely provides feedback to students).

Process quality refers to the day-to-day interactions and experiences between children and adults within an education or care-taking setting (NICHD, 2002). Environments with high quality processes are characterized as providing nurturing, developmentally-appropriate interactions, guided by evidence-based practices (NICHD, 2002; Biglan, 2015). Learning environments with high process quality are associated with improved short- and long-term outcomes, including increased social skills, higher success in education and employment, and decreased engagement in deviant and illegal behaviors, compared to environments with lower process quality (Barnett, 2004; Barnett, 2011; Biglan, 2015; Hanley, Fahmie, \& Heal, 2014; Mashburn, 2008; Vandell, Belsky, Burchinal, Vandergrift, \& Steinberg, 2010).

\section{Professional Development and Process Quality}

Process quality is ultimately composed of the ways in which people relate to others within an early childhood setting. Improving process quality requires activities or instruction that supports, improves, and maintains the behaviors of the adults that structure the social environment of early childcare settings. Such instructional activities can take the form of preservice educational opportunities that lead to certification or degrees within a child-developmentrelated field, or they can take the form of professional development activities that involve nondegree or non-certificate-seeking activities. There is evidence that formal professional 


\section{INSTRUCTIONAL PACKAGE TO PROMOTE BEHAVIOR-SPECIFIC PRAISE 6}

development activities required for degrees or certificates are not sufficient in preparing educators to provide high-quality environments. For example, Early and colleagues (2006) found few associations between early childhood educators' level of credentialing and education and process quality in their classrooms. Further, in a multi-study analysis, Early and colleagues (2007) concluded that formal education had null or contradictory effects on process quality, and they called for a renewed focus on providing professional development activities that target the specific behaviors and teaching practices that lead to high-quality environments.

One way in which educators receive professional development is through staff training. Staff training activities are considered those activities directed at improving staff's behaviors, and typically occur after staff members have already been hired. By providing staff with the knowledge and ability to engage in nurturing, developmentally appropriate, evidence-based practices, staff in turn can create excellent learning environments for their children. Staff training events can include: learning how to deliver evidence-based teaching practices such as Direct Instruction, how to effectively manage children's behaviors through packaged intervention strategies such as the Good Behavior Game, or how to use evidence-based assessments to determine the quality of the learning environments which staff create (respectively: Binder \& Watkins, 2013; Tingstrom, Sterling-Turner, \& Wilczynski, 2006; NCQTL, 2013).

\section{Positive Effects of Behavior-Specific Praise}

Improving the quality of early childcare environments through a focused professional development strategy should be guided by evidence-based practices. Best- practices for improving the process quality of staff and teachers' interactions with children have been studied for over 50 years (Hester, Hendrickson, \& Gable, 2009). Some of the most commonly researched and widely recommended best-practices include the use of praise, planned ignoring, and rule 


\section{INSTRUCTIONAL PACKAGE TO PROMOTE BEHAVIOR-SPECIFIC PRAISE 7}

reminders (Hester, Hendrickson, \& Gable, 2009; Gable, Hester, Rock, \& Hughes, 2009). The use of praise is commonly used to improve teacher-student relationships across instructional settings that range from early childhood education to graduate school (e.g., Brophy, 1981; Cameron \& Pierce, 1994; Hancock, 2002; Hester, Hendrickson \& Gable, 2009; Conroy, Sutherland, Vo, Carr, \& Ogston, 2014). Multiple reviews of the individual elements of evidence-based interventions have identified the use of praise as one of the most commonly recommended best practices for improving student compliance and on-task behaviors, reducing student defiance and disruptive behaviors, and for the prevention of the development of problem behaviors (Chorpita, \& Daleiden, 2009; Garland, Hawley, Brookman-Frazee, \& Hurlburt, 2008; McLeod, Sutherland, Martinez, Conroy, Snyder, \& Southam-Gerow, 2016). Praise is so ubiquitously recommended likely due to its ease of use, inexpensive cost, familiarity to teachers, and the powerful positive effects it has on student outcomes.

Concern regarding the potential negative impacts of praise on students' learning outcomes has been voiced. Kohn (1993) argued that all rewards stunt children's motivation to learn and hampers their self-efficacy. Kohn, therefore, strongly advocated for teachers to cease using all rewards, including praise, in the classroom. Multiple reviews have found conflicting results regarding the overall impact of rewards on students' behavior (rewards are harmful: Deci, Koestner, \& Ryan, 1999; rewards are beneficial: Cameron, Banko, \& Pierce, 2001). Despite these conflicting findings, one finding was consistent across meta-analyses: praise and positive feedback were positively associated with increases in student motivation and self-efficacy (Deci et al, 1999; Cameron et al, 2001).

\section{Professional Development to Improve Use of BSP}




\section{INSTRUCTIONAL PACKAGE TO PROMOTE BEHAVIOR-SPECIFIC PRAISE 8}

BSP has been found to promote and improve not only student self-evaluation and task motivation but has also been shown to improve academic engagement and academic performance, while simultaneously decreasing disruptive behaviors (e.g., Sutherland, Wehby, \& Copeland, 2000; Pisacreta, Tincani, Connell, \& Axelrod, 2011). Given the wide range of benefits of BSP, the rates of BSP used by teachers as reported in the literature are somewhat alarming. In a review by Jenkins and colleagues (2015), the average rate of praise (general and BSP combined) in K-12 classrooms ranged from fewer than 5 per hour to 47.3 per hour. Furthermore, the use of BSP was found to range on average from 1.7 to 8.8 per hour. These rates fall well below the goal rates chosen by teacher participants in BSP interventions, which in one study ranged from 20 to $40 \mathrm{BSP}$ per hour (Duchaine, Jolivette, \& Fredrick, 2011). Although the literature on use of BSP tends to target teachers who are already performing at sub-optimal levels, the participants are typically undergraduate students who have received direct instruction on BSP and still perform sub-optimally, or they are functioning as professional teachers who have received their terminal degree (Sutherland \& Wehby, 2001; Rathel, Drasgow, \& Christle, 2008). Early child care centers and teaching environments looking to improve their process quality would find a good starting place by increasing and improving their staff's use of BSP.

Professional development activities related to improving staff's use of BSP may include several activities or components, for example: the use of lectures on how and why teachers should use BSP, modeling or visually demonstrating the use of BSP, role-playing in which a trainer or another teacher acts as a student while the trainee teacher practices providing BSP, and in-vitro performance feedback following on the teacher's use of BSP in their classroom (Cavanaugh, 2013). Of all these components, performance feedback has been shown to reliably produce the most improvement on teachers' accuracy and use BSP (Cavanaugh, 2013). Although 


\section{INSTRUCTIONAL PACKAGE TO PROMOTE BEHAVIOR-SPECIFIC PRAISE 9}

performance feedback has consistently been shown to be the most efficacious component of training packages, it has some inherent limitations preventing its wide-spread use.

There are three major drawbacks to performance feedback given to teachers by trainers or content-area experts as the main component for professional development (Cavanaugh, 2013). First, coaching and performance feedback procedures can be time consuming, often requiring multiple days of one-on-one interactions between the teacher and the expert. It can be difficult for educators to find time in an already busy schedule to meet with an intervention coach. Second, these training procedures can be expensive because centers have to pay for the expertise of a consultant across multiple working days. This limits the accessibility of feedback-specific training to centers with adequate funding, disproportionately limiting access to non-subsidized centers in poorer areas (NICHD, 2002). Third, expert trainers are not always available for training due to other trainings scheduled, or simply due to a lack of experts in a center's geographical location. This may be especially problematic for rural areas with relatively small populations and large distances between centers and larger cities or university facilities (Connell, Sanders, \& Markie-Dadds, 1997; Subramaniam, Brunson, Cook, Larson, Poe, \& St. Peter, 2017). One solution to the limitations inherent in trainer- or expert-provided performance feedback is the use of self-monitoring, in which teachers are trained to implement a procedure and to then self-monitor their implementation of the procedure. Some studies have found selfmonitoring to be an effective method for improving teachers' use of best practices for both individual practice elements, such as behavior-specific praise, and in the accurate implementation of complete treatment packages composed of multiple best-practice elements (Hager, 2012; Simonsen, MacSuga, Fallon, \& Sugai, 2013; Oliver, Wehby, \& Nelson, 2015). 
INSTRUCTIONAL PACKAGE TO PROMOTE BEHAVIOR-SPECIFIC PRAISE 10

Recent research on the use of self-monitoring to increase teachers' use of BSP has focused on two methods: review of self-recorded video clips or in-the-moment rate recording. Sutherland and Wehby (2001) found that a training package that included instructing teachers to self-record and self-evaluate video clips of their own use of BSP, in combination with goalsetting, produced statistically and clinically significant improvements in teachers' use of BSP. One drawback to this method is that teachers must have access to a video recorder and be willing to self-record and then watch and self-evaluate their own teaching practices. To increase the accessibility of self-monitoring to improve teachers' use of BSP, a less complicated method could be useful.

A more streamlined approach was taken by Kalis, Vannest, and Parker (2007). Kalis and colleagues conducted an A-B-A single-subject treatment design with one high school teacher. They compared baseline rates of BSP to treatment rates where the teacher self-monitored their use of BSP during a math lesson. It is unclear how the teacher tracked their use of BSP, with the only information provided indicating that the teacher recorded their total amount of BSP across multiple 10-minute sessions. These sessions were scheduled in advance so that the researchers could observe the influence of self-monitoring on the teachers' use of BSP. The results suggested that BSP increased significantly when self-monitoring began, but because there was no withdrawal procedure, nor were there other participants included in the study, generalizations of the findings to other participants and contexts are limited.

Simonsen, MacSuga, Fallon, and Sugai (2013) expanded upon Kalis and colleagues' (2007) study by using a single-subjects alternating treatments design with 5 middle school teachers to determine the effectiveness of three self-monitoring strategies compared to baseline and a fourth treatment condition of "taking a day off" from self-monitoring. In the three self- 
INSTRUCTIONAL PACKAGE TO PROMOTE BEHAVIOR-SPECIFIC PRAISE 11

monitoring conditions, teachers tracked their in-the-moment use of BSP by putting a tally on a Post-It note or clipboard each time they used BSP, pressing a button on a golf counter after each BSP, or estimating the rate, on a scale of 0-4 per minute, of how many BSP they delivered in a 15-minute lesson. All conditions except for taking the day off from self-monitoring produced increases in the teachers' rate and accurate use of BSP. Use of the golf counter produced the highest rate change, followed by tallying and estimating, respectively. The teachers also provided ratings on social validity measures indicating which procedures they thought were the easiest to use, which produced the most positive impact on their students, and which method they would endorse for other teachers to use. All methods were rated positively with the use of the counter having the highest acceptability and endorsement ratings, followed by estimating, and tallying, respectively.

There are some limitations present in Simonsen and colleagues' (2013) study. First, replicating the effects of self-monitoring on five teachers is an excellent step towards generalizability, and satisfies the recommended minimum of three attempts to demonstrate functional relationships between independent and dependent variables according to Kratochwill and colleagues' (2010) best-practice recommendations for single-case design research. However, one of the next steps to be taken is to expand the findings to a group-design study, allowing for potentially greater generalization of results. Second, both Kalis and colleagues' (2007) and Simonsen and colleagues' (2013) methods involved clear pre-observation cues or prompts for participants to begin using the self-monitoring strategies. Kalis and colleagues (2007) reported providing their participant with a reminder, including examples of BSP to use, immediately prior to the start of each observation session. Simonsen and colleagues (2013) did not provide their participants with reminders, but they did schedule all observations with teachers, indicating that 
INSTRUCTIONAL PACKAGE TO PROMOTE BEHAVIOR-SPECIFIC PRAISE 12

the teachers would be observed by the researchers during the same 15-minute period of instruction each day visited. Both of these methods were essential to ensure researchers could collect the necessary data form the teachers. However, they also limit the extent to which the results can be generalized to settings where teachers receive training on the use of selfmonitoring and BSP when researcher-determined follow-ups and prompts are not explicitly scheduled. It could be the case that scheduled interactions with researchers may promote participant reactivity, where participants associate the researchers' presence with the researchers' purpose - to observe the teachers' use of BSP. Observer reactivity is rarely discussed by researchers as a factor potentially limiting findings' external validity, but needs to be addressed to maximize the adoptability of efficacious professional development strategies (but for the rare experimental test of observer reactivity on feedback via coaching for classroom management techniques, see Codding, Livanis, Pace, \& Vaca, 2008). Third, both training methods described involved a one-on-one brief workshop between a researcher and a teacher, thus requiring geographic proximity to an expert. As mentioned earlier, access to experts limits the widespread use of training programs to those who can afford them, and to those who have geographic access to nearby experts.

The current study aims to expand upon the methods of Kalis and colleagues (2007) and Simonsen and colleagues (2013) by testing if a manualized training package containing a brief, digital instructional presentation on proper use of BSP and self-monitoring, requiring no interaction between an expert and the trainees, can increase the rate of pre-service Pre-K teachers' BSP. Furthermore, data collection for this project will remove the use of preobservation prompts and limit the amount of researcher-provided cues for teachers to use BSP and self-monitoring by indicating a window of observation time during which data will be 
INSTRUCTIONAL PACKAGE TO PROMOTE BEHAVIOR-SPECIFIC PRAISE 13

collected at various times, under the instruction that the researchers will be observing 'general teaching practices' and not BSP specifically. By not informing participants of which teaching behaviors the researchers were observing, this study also improves upon the external validity of similar studies. In sum, this study aims to create and test the efficacy of a training method in which BSP and self-monitoring procedures may be disseminated at a low cost and without geographic constraints.

\section{Research Questions:}

The current research aims to assess the effectiveness of a manualized training package that includes a brief digitally recorded instructional presentation designed to improve and increase early childhood educators' use of behavior-specific praise statements while using selfmonitoring. This study aims to answer the following eight research questions:

R1: Can a brief, pre-recorded instructional narrated slideshow increase early educator's use of behavior-specific praise statements (BSP)?

R2: Can the brief, instructional narrated slideshow get early educators to use selfmonitoring without further prompting from the researcher?

R3: How will participants rate their satisfaction with the narrated slideshow?

R4: How will participants rate the effectiveness of the narrated slideshow?

R5: How much will participants endorse the use of the narrated slideshow to be used by other early educators?

R6: How will participants rate the ease of self-monitoring?

R7: How will participants rate the effectiveness of self-monitoring?

R8: How much will participants endorse the use of self-monitoring BSP to be used by other early educators? 
INSTRUCTIONAL PACKAGE TO PROMOTE BEHAVIOR-SPECIFIC PRAISE 14

\section{Methods}

\section{Design}

This study utilized a quasi-experimental within-subjects repeated-measures pre-post design (Shadish, Cook, \& Campbell, 2002). This study consisted of two observation phases and one intervention phase. The two observation phases will be baseline and post-intervention. The intervention itself did not include direct observation of participants, and instead was a period during which participants viewed and interacted with a digital -based workshop, without direct contact with the researchers for any training purposes.

\section{Participants}

Participants were recruited from a university Nursery School in the Appalachian region. Participants were recruited through the assistance of the preschools' Directors. IRB forms were provided to all Directors and all participants, and those who provided their informed consent were allowed to participate. Participants were restricted to adults who had permission from the Nursery School's Director to regularly interact and instruct the children attending the Nursery School.

A power analysis using $\mathrm{G}^{*}$ Power was conducted to help determine the sample size necessary to detect an effect size comparable to that identified by Sutherland and Wehby (2001). To detect a cohen's $d$ of 1.5 , with an $a$ level of .05 and power set at .80 , would require a minimum of 5 total participants. The current study's anticipated sample size was 15 , which would have allowed the detectection a cohen's $d$ of .7, an effect half as drastic as that found by Sutherland and Wehby.

\section{Procedure}




\section{INSTRUCTIONAL PACKAGE TO PROMOTE BEHAVIOR-SPECIFIC PRAISE 15}

The following procedures were conducted after receiving approval from the IRB. The researchers discussed the full disclosure of the study to the Director, but not the participants. The Director was informed that the purpose of the study was to assess changes in preschool teachers' use of BSP following viewing of an instructional presentation on BSP. The Director was asked to describe the researchers' and observers' purpose as to: observe general teaching practices that get used in the preschool setting. This was done to help minimize any participant-researcher reactivity effects which may decrease the external validity of the study. Baseline observations of participants began following receipt of Director's and participants' consent. Again, participants were not informed that they were being observed specifically for their use of BSP, but that the researchers/observers were viewing their overall teaching practices to learn what preschool teachers do in the classroom. Following baseline, the Director instructed participants to view the digitally recorded instructional presentation. After all participants had viewed the presentation, post-intervention observations began. See below for detailed procedures for each stage of the study.

Observation sessions. Observation sessions took place during regular instruction hours and each observation session lasted 5 minutes. All participants were projected to have a minimum of 90 minutes' total observation across pre- and post-treatment phases. Minimum observation time per phase (pre- or post-treatment) per participant was projected to be 45 minutes. This time range is consistent with previous literature using similar group-design methods (e.g., Sutherland \& Wehby, 2001). Actual observation time varied by participant and by phase of the study, with a range of 30-55 minutes during baseline (average observation time per participant was 39 minutes), and a range of 10-55 minutes during post-intervention (average of 29 minutes per participant). All baseline observations were completed prior to any participants 
INSTRUCTIONAL PACKAGE TO PROMOTE BEHAVIOR-SPECIFIC PRAISE 16

viewing the instructional presentation on BSP. This was done to prevent the confounding effects of some participants viewing the workshop and potentially discussing its content with those who had not yet viewed the workshop. Post-treatment observations began after all participants had viewed the instructional presentation. This was done to allow for creation of a semi-randomized observation schedule that includes all participants, rather than an observation schedule determined by who watched the workshop first.

Prior to each observation session, observers followed the observer protocol (see Appendix B and C) and determined which teacher they were observing. Once situated, the observers counted down using a hand gesture 3,2, 1, start, and synchronized their timers to count to 5 minutes starting from 0:00. The observation session ended when any of the following occurred the observation time reached 5 minutes. During some sessions, the participant transitioned children away and was left with no children to interact with before 5 minutes. When this occurred, the observers simultaneously paused their timers and waited for more children to be present. If no other children came, the session was ended and was not included in the data for that teacher. Had any participants requested for the researchers to cease observations, the researchers would have immediately removed themselves. However, all participants who provided their initial consent remained for the entirety of the study.

Baseline and post-treatment observations took place within the preschool during a time when the children were engaged in teacher-led instruction, known at this preschool as "center time”. Each day the participants engaged in teacher-led instructional centers in which each teacher provided a brief task or activity for the children to complete. Children moved from one teacher to the next, completing each of the teachers' centers. There were two center times per day, one in the morning with 3- to 4-year-olds, and one in the afternoon with 4- to 5- year-olds. 
INSTRUCTIONAL PACKAGE TO PROMOTE BEHAVIOR-SPECIFIC PRAISE 17

Each center time lasted about 75 minutes. The observation schedule of participants was determined using randomization without replacement for the participants present on that day (some days only had 1 or 2 participants present, whereas others had up to 5 present). The only time a participant was observed twice in a row was if all other participants present had already been observed an equal number of times for that day. This observation schedule was varied towards the end of each observation period, such that some participants were left out of the observation schedule to accrue more observations of other participants who had been absent during previous days.

Participants' use of BSP was recorded using pen-and-paper frequency data sheets (see Appendix A for data collection sheet). The data collection sheets have a column indicating the time, use of BSP, use of GP, Inter Observer Agreement (IOA), and rows breaking the observation session into 30-second bins. At the bottom of each 5-minute block within the data sheets is also a space for the observers to indicate if they observed the participants using a selfmonitoring technique (see instructional presentation section below).

Instructional package. After all participants were viewed during baseline for a minimum of 30 minutes each (the 45-minute threshold proposed would have left too few observation days to complete data collection during post-intervention), the researchers gave the Director a director's handbook which contains directions for how the director can use the materials to help their staff learn to use self-monitoring and BSP (see Appendix I for all materials). After providing the handbook to the director, the researchers pointed out that there was a checklist for the minimum-required components of training package that should be followed (see Appendix G), which included participants acknowledging they have received a golf counter (provided to the Director by the researcher), have observed the instructional 
INSTRUCTIONAL PACKAGE TO PROMOTE BEHAVIOR-SPECIFIC PRAISE 18

presentation, and for this study's purposes, completed an online survey rating their satisfaction with the training presentation. The supplemental material in the training package were left to the Director's discretion whether to use them or not - and only the daily tracking logs that allow participants to indicate their day's use of BSP was used, but was not monitored by the Director nor the researchers.

The setting for viewing the instructional presentation was in a relatively isolated office room located within the preschool, so as not to distract from ongoing teaching practices. Participants individually viewed the presentation and accessed the post-presentation survey on a laptop provided by their Director.

The pre-recorded training presentation described the benefits and use of BSP, as well as how to use a golf counter (an analog counter with a button that advances the count by one per each click) to self-monitor use of BSP. Brief vignettes of educators using BSP to improve children's behavior were used as examples of BSP in practice. The presentation was structured similarly to the lectures described in the literature and included definitions, examples, and nonexamples of BSP (e.g. Sutherland \& Wehby, 2001; Kalis et al, 2007; Rathel, Drasgow, \& Christle, 2008; Fullerton, Conroy, \& Correa, 2009; Simonsen et al, 2013).

After viewing the presentation, participants were asked to follow a link to an online survey that asked them to report their perceived quality and value of the presentation (see Appendix D).

Researchers did not observe participants while they watched the digital instructional presentation. Furthermore, the researchers provided no instruction to the teacher participants, and the only support provided to the Director in how to use the training materials was technical in nature - that is, the researchers ensured the Director could access the materials but did not 
INSTRUCTIONAL PACKAGE TO PROMOTE BEHAVIOR-SPECIFIC PRAISE 19

indicate to the Director how they ought to be used. Instructional contact between researchers and participants was eliminated to mimic situations in which expert interactions would otherwise not be available (i.e., an early educator viewing the instructional presentation in their home or classroom setting in a rural area that does not have access to the presentation's creator).

\section{Measures}

Teacher praise statements. Trained external observers recorded the types of praise statements participants used with the children in their care.

General praise. General Praise (GP) was defined as any praise statement that met the definition for a BSP (see below) but did not specify the behavior being praised. For example, "Wow Lucas, that's wonderful!" does not specify the behavior, but would have been recorded as a general praise statement because it is positive, is directed at one or more students, and is contingent on behavior.

Behavior-specific praise. Behavior specific praise (BSP) was defined using the same definition as Simonsen and colleagues (2013): "any audible, specific, and positive verbal feedback to one or more students contingent on behavior" (p. 7). Here, specific was defined as including some portion or description of the behavior that was being praised. One limitation was added, such that all components must have been included in the statement for it to be a BSP, and in order for multiple BSPs to be counted within a 5-s window, the new BSP had to specify either a new specific behavior, or have been directed to a different child. Such that a teachers' praise of "Wow Lucas, wonderful drawing! I really like the way you drew that cat!" would have been counted as one BSP, whereas "Wow Lucas, wonderful drawing! [turning to Jordan] I really like the way you [Jordan] drew that cat!" would have been counted as two BSPs. Additionally, any 
INSTRUCTIONAL PACKAGE TO PROMOTE BEHAVIOR-SPECIFIC PRAISE 20

BSP phrases that contained GP phrases were only coded as BSP, because all elements of GP are subsumed under the more stringent requirements of BSP.

Observer reliability and agreement. Observers trained for reliability by observing the participants from the current study. Observers were considered reliable and ready for study observations when they reached and maintained 85\% Interobserver Agreement (IOA) for both BSP and GP across 3 consecutive sessions each for two different participants. Reliability of observations was tracked using the IOA Tracking Sheet (see Appendix C). These instructions, including how IOA was calculated, are represented in detail in Appendix B. A total of three observers achieved study reliability as defined above.

Prior to initiating the study observation session, observers situated themselves so that they had a direct visual line of the participant and the children the participant was working with. Observers moved themselves to be close enough to hear vocal exchanges between the participants and the children. After synchronously initiating their timers, observers tracked the frequency of BSP and GP statements in 30-seconds bins (see Appendix A for BSP Data Collection Sheet). At the end of the session, observers calculated interobserver agreement (IOA) for that session, using the 'mean count per interval IOA \%' formula provided by Cooper, Heron, and Heward (2014).

Observers used the observation protocol set forth in Appendix B when more than one observer was present during the session. A projected minimum of $33 \%$ of both baseline and postintervention phases were to have two trained observers independently collecting data. However, due to scheduling issues, IOA was collected for only $24 \%$ of baseline and $25 \%$ of postintervention observations. If IOA dropped below $80 \%$ for any data collection session, booster 
INSTRUCTIONAL PACKAGE TO PROMOTE BEHAVIOR-SPECIFIC PRAISE 21

training sessions were conducted, preferably while observing that same participant, until a minimum of $85 \%$ IOA was again achieved, prior to observing another study session.

Participant's use of self-monitoring. Participants' use of self-monitoring was recorded by observers during observations. There was a designated space on the observation data sheets for each observed session that allowed observers to indicate if participants had a golf counter present during the session (see Appendix A).

Instructional presentation satisfaction. Following viewing the instructional presentation, participants accessed an online post-presentation survey that asked them to appraise the effectiveness, quality, and change in content knowledge attributable to the presentation (see Appendix D for survey questions).This satisfaction survey used 12 Likert-type items to ask participants how strongly they agreed or disagreed with a statement about the presentation, such as "The presentation made it easy to understand what behavior-specific praise is". Each item is anchored on a scale from 1 to 5, indicating respectively, that participants either Strongly Disagree, Somewhat Disagree, Neither Agree nor Disagree, Somewhat Agree, or Strongly Agree with the item.

Intervention satisfaction. After all participants completed all phases of the study (baseline, instructional presentation, and post-intervention), they were asked to complete a poststudy survey with a total of 28 items (see Appendix E). Items on this survey asked participants to rate how strongly they agreed with statements related to their experiences using behaviorspecific praise and self-monitoring. These items targeted participants' perceptions of the ease of implementation of the intervention( 8 items; ex: "I think using behavior-specific praise was worth the effort"), participants' endorsement of the intervention (6 items; ex: "I would recommend other preschool teachers use behavior-specific praise"), their perceived positive and negative 
INSTRUCTIONAL PACKAGE TO PROMOTE BEHAVIOR-SPECIFIC PRAISE 22

effects of the intervention (10 items; ex: "I think there are undesirable effects on my own teaching when I use behavior-specific praise"), and how well they understood the two primary components of the intervention - use of BSP, and use of self-monitoring (4 items; ex: "I understand how to use self-monitoring"). Questions for this survey were derived from two sources. First, the Teacher Acceptability Rating Form - Revised version was used to guide questions regarding ease of implementation, endorsement of the intervention, effects of the intervention, and understanding of the components of the intervention (TARF-R; Reimers \& Wacker, 1988). Second, items from Simonsen et al (2013) were adapted to determine participants' perceptions of ease of implementation and endorsement of the intervention. Each item was anchored on a scale from 1 to 5, indicating respectively, that participants either Strongly Disagree, Somewhat Disagree, Neither Agree nor Disagree, Somewhat Agree, or Strongly Agree with the item.

Proposed Selected interviews. A purposive sample of participants was to be selected for follow-up interviews based on the relative change in their use of BSP (See Appendix F for interview schedule). Following the post-workshop observation phase, participants were asked if they would be willing to be interviewed to discuss their experiences using BSP and selfmonitoring. A minimum of three participants were to be selected for interviews using the following purposive sampling criteria: one participant with the greatest improvement in use of $\mathrm{BSP}$, one with the median improvement in use of BSP, and one with the least improvement in BSP. Purposive sampling allows for a meaningful range of participants to be selected, to help identify intervention characteristics that may have facilitated some but not all participants' change in their use of BSP (Miles, Huberman, \& Saldaña, 2014). 
INSTRUCTIONAL PACKAGE TO PROMOTE BEHAVIOR-SPECIFIC PRAISE 23

All interviews were to be audio recorded and transcribed for analysis. Only one participant agreed to an interview, but they did not respond to the researchers' attempts to schedule a meeting. No interviews took place.

\section{Plan of Analyses}

Means, standard deviations, and descriptive statistics were used for survey-response items. A multilevel modelling (MLM) approach was used to analyze change in teachers' use of BSP from baseline to post-intervention phases for multiple reasons. First, due to scheduling and attendance issues, there were an unequal number of sessions collected across pre- and postintervention phases. Second, there were an unequal number of sessions between participants. The ANOVA framework requires equal numbers of observations across phases and between participants. To fit the current data set into an ANOVA framework would require a significant loss of data. Multilevel modelling does not require equal numbers of observations across phases and between participants, allowing the full dataset to be retained and analyzed. Third, multilevel modelling inherently accounts for nesting of observations within the same participant, thereby removing statistical error generated by correlations between observations of the same participant (Raudenbush \& Bryk, 2002).

Had interviews taken plan, qualitative data from interviews would have been transcribed and coded for themes relevant for informing research questions.

R1: Can a brief training package with an instructional presentation increase early educators' use of behavior-specific praise statements (BSP)?

$\mathrm{H}_{1}$ : Participants' use of BSP will increase following their viewing of the instructional presentation, compared to baseline levels of BSP. This hypothesis will be tested with multilevel modelling. 
INSTRUCTIONAL PACKAGE TO PROMOTE BEHAVIOR-SPECIFIC PRAISE 24

R2: Can the brief training package with an instructional presentation get early educators to use self-monitoring without further prompting from the researcher?

$\mathrm{H}_{2}$ : Participants will use the golf counters to self-monitor their use of BSP. This hypothesis will be assessed by observing and recording how frequently participants will have their golf counter with them during observation sessions. Descriptive statistics will be presented.

R3: How will participants rate their satisfaction with the instructional presentation? $\mathrm{H}_{3}$ : Participants will be generally satisfied with the workshop. This will be assessed using items from the post-presentation survey and analyzed using descriptive statistics.

R4: How will participants rate the effectiveness of the instructional presentation? $\mathrm{H}_{4}$ : Participants will rate the workshop as generally effective. This will be assessed using items from the post-presentation survey and analyzed using descriptive statistics.

R5: How much will participants endorse the use of the instructional package to be used by other early educators?

$\mathrm{H}_{5}$ : Participants will strongly endorse the use of the training package to be used by other early educators. This will be assessed using items from the post-study survey and analyzed using descriptive statistics.

R6: How will participants rate the ease of self-monitoring?

$\mathrm{H}_{6}$ : Participants will rate use of the golf clicker to self-monitor their use of BSP as moderately to fairly easy. This will be assessed using items from the post-study survey. 
INSTRUCTIONAL PACKAGE TO PROMOTE BEHAVIOR-SPECIFIC PRAISE 25

R7: How will participants rate the effectiveness of self-monitoring?

$\mathrm{H}_{7}$ : Participants will rate use of the golf counter to self-monitor their use of BSP as effective. This will be assessed using items from the post-study survey.

R8: How much will participants endorse the use of self-monitoring BSP to be used by other early educators?

$\mathrm{H}_{8}$ : Participants will moderately to strongly endorse the use of self-monitoring BSP to be used by other early educators. This will be assessed using items from the post-study survey.

\section{Results}

\section{Participant Demographics}

A total of 13 undergraduate students participated in this study. All students were enrolled in a Child Development and Family Studies course which serves to prepare students for professional competences in working with children aged birth to 5 years old. In this course, students regularly taught lessons and interacted with children attending the university's nursery school, whose ages ranged from 3- to 5- years old. Throughout the semester, the students received regular supervision from credentialed faculty and staff, including 3 hours of mentoring per week from the Nursery School Director, who had a Doctorate in Early Childhood Education.

Specific demographic information were collected during the post-presentation survey. Of the 13 participants, 11 completed all or parts of the post-presentation survey. All respondents self-identified as female. Most respondents identified their ethnicity as White or Caucasian $(\mathrm{n}=$ 9), one identified as African American and Caucasian, and one chose not to respond.

Respondents' ages ranged from 20 to 23 years, with a mean of 21.63. Ten respondents reported their major as Child Development and Family Studies, and one reported their major as Child 
INSTRUCTIONAL PACKAGE TO PROMOTE BEHAVIOR-SPECIFIC PRAISE 26

Development and Family Studies and Special Education. All respondents were concurrently enrolled in undergraduate courses at their local university, and were upper-classmen (Juniors $n=$ 3, Seniors $n=8$ ) and one respondent had already earned a bachelor's degree. In sum, this sample's demographics were mostly homogeneous with regards to gender, ethnicity, age, educational background and major, and highest education level attained.

\section{Observed Use of BSP and self-monitoring (RQ 1-2)}

\section{R1: Can a brief training package with an instructional presentation increase early} educators' use of behavior-specific praise statements (BSP)? Observational data on participants' use of behavior-specific praise (BSP) were collected for all 13 participants during pre- and post- intervention phases. As described in the Methods section, observers were considered reliable when their level of Interobserver Agreement (IOA) was greater than $85 \%$ on both BSP and general praise across three consecutive sessions, for two different participants. It took 28 pre-baseline sessions for the first pair of observers to achieve study reliability, and 17 sessions for a third observer to reach study reliability. A total of 179 5-minute study observation sessions were collected (101 baseline, 77 post-intervention). A second independent observer was present for 45 sessions, or $25.1 \%$ of all sessions. This percent of sessions with IOA falls within the acceptable range according to current standards for observational studies (Ktratochwill et al., 2013). IOA was calculated to be $94.67 \%$ for BSP, which exceeds the standard for acceptable IOA (Kratochwill et al., 2013). A multilevel modelling (MLM) approach was used for reasons described above (see Plan of Analyses) to assess change in use of BSP from baseline to postintervention phases. The steps and results of the MLM process are described next.

Null model. To determine how much of the total variance in use of BSP was attributable to differences in use of BSP between participants, a null model was run to calculate 
INSTRUCTIONAL PACKAGE TO PROMOTE BEHAVIOR-SPECIFIC PRAISE 27

an Intraclass Correlation Coefficient (ICC; Raudenbush \& Bryk, 2002). The outcome variable for the multilevel model was TotalBSP, which was the number of observed uses of BSP during a single 5-minute session. Conceptually, the null model provides the average use of BSP for all participants across all phases of the study. The structural equation for the null model is shown in equation 1:

$$
\text { BSPTotal }_{i j}=\beta_{0 j}+r_{i j}
$$

Where

$\beta_{0 \mathrm{j}}=\gamma_{00}+\mathrm{u}_{0 \mathrm{j}}$

The results of this model are shown in Table 1. The ICC for this model was calculated using equation 2:

$$
I C C=\frac{\tau 00}{\tau 00+\sigma 2}
$$

The percentage of between-participant variance in BSPTotal was $100 *[.35 /(.35+1.35)]=21 \%$.

Piecewise model. A piecewise model was constructed to account for two level one timevarying covariates: PostWeek1, which included all observations collected during the first week immediately following participants' use of the instructional presentation, and PostWeek2, which included all observations collected during the second week following use of the instructional presentation. These time-varying covariates were used because the first week following implementation of the intervention was also the last week during which participants had graderelevant responsibilities for their course. Multiple participants admitted to 'being checked out' of school and responsibilities during the second week following the intervention, after they had submitted everything which would be used to calculate their grades. This was interpreted by the researcher as a potential source of a loss of motivation to provide high-quality interactions with 
INSTRUCTIONAL PACKAGE TO PROMOTE BEHAVIOR-SPECIFIC PRAISE 28

the children attending the Nursery School, and was therefore coded as a time frame separate from the first week following the intervention.

The full model used to address R1 utilized a slopes-as-intercepts piecewise organizational model with PostWeek1 and PostWeek2 serving as level-one time-varying covariates. The structural model is shown in equation 3:

$$
\text { BSPTotal }_{\mathrm{ij}}=\beta_{0 \mathrm{j}}+\beta_{1 \mathrm{j}}(\text { PostWeek1 })+\beta_{2 \mathrm{j}}(\text { PostWeek } 2)+\mathrm{r}_{\mathrm{ij}}
$$

Where

$\beta_{0 \mathrm{j}}=\gamma_{00}+\mathrm{u}_{0 \mathrm{j}}$

$\beta_{1 j}=\gamma_{10}$

$\beta_{2 \mathrm{j}}=\gamma_{20}$

In this model, the intercept $\left(\beta_{0 \mathrm{j}}\right)$ represents the average use of BSP for a 5-minute observation during the baseline phase. The slopes of this model $\left(\beta_{1 \mathrm{j}}\right.$ and $\left.\beta_{2 \mathrm{j}}\right)$ represent the average increase in BSP use during the first week post-presentation (PostWeek1) and the second week postpresentation (PostWeek2). The coding scheme used for the slopes-as-intercepts Level-1 variables is shown in Table 2.

Results for this piecewise model are shown in Table 3. All intercepts and slopes were found to be statistically significant. The average number of BSPs during pre-treatment is indicated by $\gamma_{00}$, which was $0.56(p<.05)$. This indicates that on average, participants provided 0.56 BSP statements for roughly every 5 minutes of observation, or an average of slightly more than one BSP every 10 minutes.

To calculate the rate of BSP during the first week following the presentation, the equation BSPTotal $_{i j}=\beta_{0 \mathrm{j}}+\beta_{1 \mathrm{j}}($ PostWeek1) was used. The average increase in use of BSP is indicated by $\gamma_{10}=1.60$. Combining the intercept term with the slope-as-intercept term yields an average use 
INSTRUCTIONAL PACKAGE TO PROMOTE BEHAVIOR-SPECIFIC PRAISE 29

of BSP of $2.16(p<.001)$ for every 5-minute observation, or an average of more than four BSP every 10 minutes. This is an increase in BSP by over $380 \%$.

To calculate the rate of BSP during the second week following treatment, the equation BSPTotal $_{\mathrm{ij}}=\beta_{0 \mathrm{j}}+\beta_{1 \mathrm{j}}($ PostWeek1 $)+\beta_{2 \mathrm{j}}($ PostWeek2) was used. The average change in use of BSP during the second week is indicated by $\gamma_{20}=-0.77(p<.001)$. Combining the intercept term with both slopes-as-intercepts terms yields an average use of BSP of 1.39 for every 5-minute observation, which is a decrease of $64 \%$ from the first week of treatment, but still represents an average increase in BSP over baseline by $240 \%$.

For a comparison of within-participant change, baseline and post-presentation average rates of use of BSP were calculated for each participant and are displayed in Figure 1. Eight of 13 participants increased their use of BSP from baseline to post-intervention. Two participants used BSP less during post-intervention, and three participants did not use BSP during the postpresentation phase. Of the three participants who did not use BSP during post-presentation, one did not use BSP during baseline and never had a counter present during post-presentation sessions, whereas the other two and had low rates of BSP use during baseline and had a counter present during $100 \%$ and $83 \%$ of their sessions, respectively. See the next section for an analysis of participants' use of self-monitoring.

Based on these results, it is concluded that the brief instructional presentation and supplemental materials provided in the instructional package (e.g., golf counters, Teachers' Workbook, Director's Handbook) resulted in an average increase in participants' use of BSP. However, individual differences resulted in varying degrees of benefit, and not all participants demonstrated an increase in their use of BSP and use of self-monitoring. 
INSTRUCTIONAL PACKAGE TO PROMOTE BEHAVIOR-SPECIFIC PRAISE 30

\section{R2: Can the brief training package with an instructional presentation get early} educators to use self-monitoring without further prompting from the researcher? The Nursery School Director prompted participants to use their counters to self-monitor their use of BSP while engaging with children during teacher-led instruction. The researcher did not provide prompts to the Director nor the participants to use counters. For each observational session, data collectors indicated if participants had a counter immediately accessible. If a counter was present, the observer indicated so on their data collection sheet (Appendix A). For all preintervention observations, no counters were present. Counters were present during 56 (71.43\%) of all post-intervention observations. Percentages of counter use ranged from $0-100 \%$ of observed sessions, with12 out of 13 participants having a counter present during at least $60 \%$ of the sessions observed. Four participants had a counter present in $100 \%$ of observed sessions, five had a counter present during $70-83 \%$, three during $63-70 \%$, and one for $0 \%$ of sessions. Overall, the training package with the instructional presentation did successfully result in participants' using self-monitoring to track their use of BSP, without further prompting from the researcher.

\section{Participant Ratings of Instructional Presentation (RQ 3-5)}

\section{R3: How will early educators rate their satisfaction of an instructional presentation}

on BSP? Immediately following their watching of the instructional presentation, participants were asked to fill out a post-presentation survey. This survey included demographics questions as well as questions regarding the presentation, behavior-specific praise, and self-monitoring. Data from this survey were used to answer research questions 3 through 5. Eleven participants initiated the survey, and 10 respondents completed the survey. The one participant that did not 
INSTRUCTIONAL PACKAGE TO PROMOTE BEHAVIOR-SPECIFIC PRAISE 31

complete the survey provided only demographics information, and did not answer items related to the presentation, BSP, nor self-monitoring.

Three items were used to determine participants' satisfaction with the instructional presentation, they included:

1. Overall, I was satisfied with the presentation.

2. The presentation was interesting.

3. The presentation was boring.

For each item, participants were asked to rate how strongly they agree or disagree, on a 5-point Likert scale ranging from 1 "Strongly Disagree" to 5 "Strongly Agree". Higher scores indicated higher endorsement of the item statement. Table 4 shows the means, standard deviations, and response distribution for each item. These items were combined to create a presentation satisfaction scale, using reverse coding for the item that described the presentation as boring. Scale reliability was calculated using Cronbach's alpha, and was found to be good, $\alpha=.85$, suggesting that there is enough shared variability in how participants answered each item so that it is not inappropriate to take the results from each of these items and apply them to same research question (Taber, 2017). The presentation satisfaction scale mean was $3.8(S D=1.21)$, indicating higher-than-neutral satisfaction. Analyses for each item are presented below.

Overall satisfaction was high $(M=4.40)$, with 9 of the 10 respondents indicating somewhat or strong agreement, with one respondent indicating they neither agreed nor disagreed. Respondents rated the presentation, on average, as more interesting than neutral $(M=3.70)$, with only 6 indicating somewhat or strong agreement. Finally, the presentation on average was not rated as boring $(M=2.70)$. However, 3 respondents either somewhat or strongly agreed that it was boring. Overall, participants were neutral to satisfied with the presentation. 
INSTRUCTIONAL PACKAGE TO PROMOTE BEHAVIOR-SPECIFIC PRAISE 32

\section{R4: How will early educators rate the effectiveness of an instructional presentation}

about BSP? Five items from the post-presentation survey were used to address research question 4: "How will participants rate the effectiveness of the instructional presentation?" They included:

1. Before I watched the presentation, I didn't know much about behavior-specific praise.

2. The presentation made it easy to understand what behavior-specific praise is.

3. The presentation helped me to understand what behavior-specific praise is.

4. The presentation helped me learn how to use behavior-specific praise.

5. The presentation helped me learn how to self-monitor my use of behavior-specific praise while I teach.

The first item addressed the potential need for such a presentation by assessing participants' selfreported lack of knowledge about behavior-specific praise. The last four items addressed participants' perceptions of the impact of the presentation on their knowledge and understanding of behavior-specific praise and self-monitoring.

The same response scale was used for these items as the items addressing RQ3, where higher scores indicated higher endorsement of the item statement ( $1=$ "Strongly Disagree", $5=$ Strongly Agree"). Items 2 through 5 for this research question were combined to create a presentation effectiveness scale. Scale reliability was good, $\alpha=.92$, indicating it may not be inappropriate to combine analyses of these items to answer the same research question. The presentation effectiveness scale mean was $4.4(S D=.59)$, suggesting that participants believed the presentation was effective at improving understanding of BSP and use of self-monitoring. Analyses of individual items are presented below.

Table 5 shows the means, standard deviations, and response distribution for each item. The first item about participants' prior knowledge of BSP had the widest range of responses (1 to 4) and 
INSTRUCTIONAL PACKAGE TO PROMOTE BEHAVIOR-SPECIFIC PRAISE 33

the largest standard deviation (1.00). This indicates participants were not homogeneous in their prior knowledge of BSP. One participant strongly disagreed that they didn't know much about BSP before the presentation (suggesting that they did indeed know about BSP prior to the presentation), three participants somewhat disagreed, two neither agreed nor disagreed, and four somewhat agreed.

Means and standard deviations were similar (ranges $4.20-4.60$ and $.52-.67$, respectively) for the four remaining items about the effectiveness of the presentation. All participants who completed the post-presentation survey either somewhat agreed $(n=4)$ or strongly agreed $(n=6)$ that the presentation made it easy for them to understand BSP. Nine of the 10 participants somewhat agreed $(n=6)$ or strongly agreed $(n=3)$ that the presentation also helped them to understand what BSP is, with only the participant who indicated they already had knowledge of BSP neither agreeing nor disagreeing that the presentation helped them to understand BSP. Nine of the 10 participants also somewhat agreed $(n=5)$ or strongly agreed $(n$ =4) that the presentation helped them understand how to use BSP, with the participant who already had knowledge of BSP neither agreeing nor disagreeing that the presentation helped them understand how to use BSP. Finally, all ten participants either somewhat agreed $(n=5)$ or strongly agreed $(n=5)$ that the presentation helped them learn how to use self-monitoring.

Overall, the instructional presentation was effective in increasing participants' perceptions of their knowledge of BSP, including their perceived knowledge of how to use BSP and how to use self-monitoring their use of BSP.

R5: How much will early educators endorse the use of instructional presentation for BSP training to be used by other early educators? Data to answer research question 5 were collected using a single item from the post-presentation survey: "I would recommend the 
INSTRUCTIONAL PACKAGE TO PROMOTE BEHAVIOR-SPECIFIC PRAISE 34

presentation to other preschool teachers." The same response scale was used for this item as the items addressing R3 and R4, where higher scores indicated higher endorsement of the item statement. The average response score for this item was 4.20, with a standard deviation of .92. Nine of the ten participants either somewhat agreed $(n=5)$ or strongly agreed $(n=4)$ that they would recommend the presentation to others. One participant, who was the same participant with a higher perceived prior knowledge of BSP as indicated in R4 above, indicated that they

somewhat disagreed that they would recommend the presentation to others. Overall, it was found that participants would endorse the use of this presentation to be used by other early educators.

\section{Participant Ratings of Use of Self-Monitoring and BSP (RQ 6-8)}

Research Questions 6, 7, and 8 are summative. Participants rated their experiences using self-monitoring of BSP use. Data used to answer Research Questions 6, 7, and 8 were collected at the end of the data collection period, following all observation sessions, and at the end of the school semester. This allowed participants to have two weeks to implement self-monitoring of BSP. Data were collected using the post-study survey (Appendix E), where participants were asked to rate how strongly they agreed or disagreed with each item on a 5-point Likert scale ranging from 1 "Strongly Disagree" to 5 "Strongly Agree".

A total of 11 participants initiated or filled out the post-study survey. One respondent answered the first question "I liked using BSP" with "Somewhat Disagree" and all subsequent questions with "Strongly Disagree". Some items were reverse-coded, i.e., "I think there are disadvantages to using self-monitoring" versus "I think using self-monitoring was worth the effort"; so this participant's responses were excluded from analyses. Another participant began the survey but did not answer any questions, leaving a total sample of nine participants' responses to be included in the following analyses. 
INSTRUCTIONAL PACKAGE TO PROMOTE BEHAVIOR-SPECIFIC PRAISE 35

R6: How will early educators rate the ease of self-monitoring? Data to answer

research question 6, "How will early educators rate the ease of self-monitoring?", were collected using four items from the post-study survey. They included:

1. It was easy for me to use self-monitoring.

2. I think using self-monitoring was worth the effort.

3. I experienced discomfort when trying to use self-monitoring.

4. I think there are disadvantages to using self-monitoring.

These items were combined to create an ease of self-monitoring scale. Items 3 and 4 were reverse coded. Scale reliability was good, $\alpha=.82$, indicating it may not be inappropriate to combine analyses of these items to answer the same research question. The ease of selfmonitoring scale mean was $3.75(S D=1.11)$. Analyses of individual items are presented below.

See Table 6 for means, standard deviations, and response distributions for each item. The mean rating for the item "It was easy for me to use self-monitoring" was just above Neither Agree nor Disagree at 3.89. One participant Strongly Disagreed while the remaining participants either Somewhat Agreed $(n=6)$ or Strongly Agreed $(n=2)$ that self-monitoring was easy to use. The mean rating for the item "I think using self-monitoring was worth the effort" was above Somewhat Agree at 4.22. One participant Somewhat Disagreed but the remaining eight participants Somewhat Agreed $(n=4)$ or Strongly Agreed $(n=4)$ that self-monitoring was worth the effort.

The mean rating for the reverse-coded item "I experienced discomfort when trying to use self-monitoring," with low scores being better, was below Neither Agree nor Disagree at 2.67. Four participants either Strongly $(n=3)$ or Somewhat Disagreed $(n=1)$, one Neither Agreed nor Disagreed, and three either Somewhat $(n=3)$ or Strongly Agreed $(n=1)$ that they experienced 
INSTRUCTIONAL PACKAGE TO PROMOTE BEHAVIOR-SPECIFIC PRAISE 36

discomfort while using self-monitoring. The mean rating for the reverse-coded item "I think there are disadvantages to using self-monitoring" was also below Neither Agree nor Disagree at 2.77. The majority of participants rated the items as Neither Agreed nor Disagreed $(n=4)$.

Three participants Strongly Disagreed or Somewhat Disagreed while two Somewhat Agreed that there were disadvantages to self-monitoring.

Overall, it was found that for the participants self-monitoring was somewhat easy to use but did create some discomfort and some disadvantages while using it; but is generally was rated as worth the effort involved.

R7: How will early educators rate the effectiveness of self-monitoring? Data used to answer research question 7 "How will early educators rate the effectiveness of self-monitoring?" were collected using four items from the post-study survey:

1. I think the children I work with experienced discomfort when I used self-monitoring.

2. I experienced discomfort when trying to use self-monitoring

3. I think there are undesirable effects on my own teaching when I use self-monitoring.

4. I think self-monitoring has left a long-lasting positive impact on my teaching.

Items 1, 2, and 3 were reverse-coded and all resulting scores were combined to create a scale measuring the impact of self-monitoring on teaching. Scale reliability was low, $\alpha=.55$, indicating it may be inappropriate to combine analyses of these items to answer the same research question. The impact of self-monitoring on teaching scale had a mean of $3.58(S D=$ 1.08), suggesting some participants overall experienced negative impacts, and others overall experienced no negative impacts of self-monitoring on their teaching. However, given the low reliability of this scale, individual item analyses may provide more meaningful information. Analyses of individual items are presented below. 
INSTRUCTIONAL PACKAGE TO PROMOTE BEHAVIOR-SPECIFIC PRAISE 37

See Table 7 for non-reverse-coded means, standard deviations, and response distributions for each item. The mean rating for item "I think the children I work with experienced discomfort when I used self-monitoring" was below Neither Agree nor Disagree at 2.11. Five participants either Strongly or Somewhat Disagreed, three Neither Agreed nor Disagreed, and one Somewhat Agreed that self-monitoring was a source of discomfort for children. The mean rating for "I experienced discomfort when trying to use self-monitoring" was below Neither Agree nor Disagree at 2.67. One participant Strongly Agreed, two Somewhat Agreed, two Neither Agreed nor Disagreed, one Somewhat Disagreed, and three Strongly Disagreed. The mean rating for item "I think there are undesirable effects on my own teaching when I use self-monitoring" was also below Neither Agree nor Disagree at 2.44. Five participants either Strongly or Somewhat Disagreed, three Neither Agreed nor Disagreed, and one Somewhat Agreed that self-monitoring interfered with their teaching. The mean rating for item "I think self-monitoring has left a longlasting positive impact on my teaching" was above Neither Agree nor Disagree at 3.67. Five participants Neither Agreed nor Disagreed, and two each Somewhat or Strongly Agreed that selfmonitoring would have a lasting positive effect on their teaching.

Overall, we conclude that self-monitoring was perceived to have few or no negative impacts on children and most of the participants' teaching, but produced some undesirable effects for a minority of participants' teaching, and nearly half the participants were not completely comfortable with using the technique while teaching. Finally, self-monitoring was perceived to produce some long-lasting positive effects on some participants' teaching.

R8: How much will early educators endorse the use of self-monitoring BSP to be used by other early educators? 
INSTRUCTIONAL PACKAGE TO PROMOTE BEHAVIOR-SPECIFIC PRAISE 38

Data to answer research question 8 "How much will early educators endorse the use of self-monitoring BSP to be used by other early educators?" were collected using 8 items from the post-study survey:

1. I liked using behavior-specific praise.

2. I liked using self-monitoring.

3. I am willing to use behavior-specific praise with my future students.

4. I am willing to use self-monitoring in my future teaching settings.

5. I think other preschool teachers would want to use behavior-specific praise.

6. I think other preschool teachers would want to use self-monitoring.

7. I would recommend other preschool teachers use behavior-specific praise.

8. I would recommend other preschool teachers use self-monitoring.

These items were combined to create a BSP and self-monitoring endorsement scale. Scale reliability was acceptable but not high, $\alpha=.66$, indicating it may not be inappropriate to combine analyses of these items to answer the same research question, but that items- level analyses should also be taken into account. The endorsement of BSP and self-monitoring scale had a mean of $4.51(S D=.65)$, suggesting participants highly endorsed these practices. Analyses of individual items are presented below.

See Table 8 for means, standard deviations, and response distributions for each item. The mean ratings for items "I liked using behavior-specific praise" and "I liked using selfmonitoring" were 4.33 and 4.22, respectively. One participant Somewhat Disagreed, while the remaining eight either Somewhat Agreed or Strongly Agreed with liking their experience with BSP. All nine participants either Somewhat Agreed or Strongly Agreed that they liked their experience with self-monitoring. 
INSTRUCTIONAL PACKAGE TO PROMOTE BEHAVIOR-SPECIFIC PRAISE 39

Mean ratings for items "I am willing to use behavior-specific praise with my future students" and "I am willing to use self-monitoring in my future teaching settings" were both 4.77 and 4.67, respectively with all nine participants reporting they either Somewhat Agreed or Strongly Agreed they would be willing to use BSP and self-monitoring in the future.

Mean ratings for items "I think other preschool teachers would want to use behaviorspecific praise" and "I think other preschool teachers would want to use self-monitoring" were 4.67 and 4.22, respectively. All nine participants either Somewhat Agreed or Strongly Agreed that other preschool teachers would want to use BSP. However, while rating if they believed other preschool teachers would want to use self-monitoring, seven participants Somewhat Agreed or Strongly Agreed while two participants Neither Agreed nor Disagreed.

Mean ratings for items "I would recommend other preschool teachers use behaviorspecific praise" and "I would recommend other preschool teachers use self-monitoring" were 4.78 and 4.44, respectively. All nine participants either Somewhat Agreed or Strongly Agreed that they would recommend others to use BSP. One participant Neither Agreed nor Disagreed, and eight either Somewhat Agreed or Strongly Agreed that they would recommend others to use self-monitoring.

Overall, we conclude that participants liked using, were willing to use in the future, anticipated other teachers would like to use, and would recommend to other teachers the use of BSP and self-monitoring. Participants overwhelmingly rated their experiences using BSP and self-monitoring as positive, with 68 out of 72 responses having a positive valence. Selfmonitoring was slightly less endorsed, with 33 out of 36 responses being Somewhat Agree or Strongly Agree, compared to, BSP which had 35 out of 36 responses being Somewhat Agree or Strongly Agree. 
INSTRUCTIONAL PACKAGE TO PROMOTE BEHAVIOR-SPECIFIC PRAISE 40

\section{Discussion}

The primary goal of this study was to determine the effectiveness and usability of a manualized, digitally-presented instructional package designed to instruct pre-service early educators. BSP was selected as the learning kernel for the instructions as it is well-established as a teaching technique that yields multiple positive benefits for children (Embry \& Biglan, 2008; Gable et al., 2009; Hester et al., 2009). The instructional package developed for this study was made with the intention of increasing the accessibility of effective professional development for rural and poor early education centers. Multiple studies examining the impact of teacher education on process quality in early childhood education settings revealed that teachers' levels of education and training had mixed results at best, with reviewers concluding that there is a need for professional development events that improve the day-to-day interactions between adults and children (Early et al., 2006; Early et al., 2007). As reviewed by Cavanaugh (2013), the professional development literature on improving teachers' use of BSP demonstrates that the most efficacious professional developments include some form of feedback, traditionally provided by an expert. However, professional development events that require an expert trainer for instruction and feedback are restrictive economically and geographically (Subramaniam, et al., 2017). Therefore, there is a clear need for professional development packages that are effective but do not inherently limit their use to exclude poor and rural education centers. The purpose of this study was to assess the effectiveness of an online professional development package that removed the need for an expert to provide in-person instruction and feedback, and instead taught participants how to use self-monitoring to improve their use of BSP, thus making this an affordable, highly-accessible professional development package. 
INSTRUCTIONAL PACKAGE TO PROMOTE BEHAVIOR-SPECIFIC PRAISE 41

The package's development was guided by Embry and Biglan's (2008) concept of the behavioral kernel - a fundamental, irreducible element of behavior change that is likely to underlie the positive effects of treatment. Researchers are more likely to develop effective and parsimonious interventions by designing treatments that use behavioral kernels. Praise was identified as a behavioral kernel by Embry and Biglan (2008) and has been supported by over 50 years of research on best-teaching-practices, and is included as a fundamental component in dozens of evidence-based interventions used by practitioners to improve the behavior and socioemotional well-being of children and adults; thus making it a priority for improving adult-child interactions (Chorpita \& Daleiden, 2009; Garland et al, 2008; McLeod et al., 2016). Rates of praise in the classroom are typically below what is considered best-practice (Jenkins et al., 2015). Therefore, improving early educators' use of BSP with children was selected for this investigation.

Researchers have studied the intricacies of how to improve teachers' use of praise for more than 40 years (e.g., Sloat, Tharp, \& Gallimore, 1977). Cavanaugh's (2013) review of this research suggests that the most effective ways of improving teachers' use of praise is through instructional packages that include the use of feedback. Instructional packages that require feedback to be provided by experts restricts its use to only those centers that have access to experts. Previous research on using self-monitoring to improve BSP (e.g., Kalis et al., 2007; Simonsen et al., 2013) have all included the use of expert-provided feedback or initial instruction, and included implicit prompts to use BSP by informing participants that their use of BSP was being monitored. The package developed and tested in this study is the first to exclude the need for experts throughout all stages of instruction and feedback, and the first to remove potential participant reactivity by not informing participants which teaching behaviors were 
INSTRUCTIONAL PACKAGE TO PROMOTE BEHAVIOR-SPECIFIC PRAISE 42

being monitored. This helps to remove limitations of access to high-quality professional development for rural centers and centers in poverty. Given this success, the use of selfmonitoring may be expanded to improve a range of teachers' use of evidence-based teaching practices (Hager, 2012; Oliver et al., 2015; Simonsen et al., 2013).

This study examined three sources of data to determine the effectiveness of the instructional package: rates of BSP, participants' perceptions regarding the instructional presentation, and participants' perceptions regarding the use of BSP and self-monitoring. Participants increased their use of BSP by over $380 \%$ during the first week of using selfmonitoring, compared to baseline rates. There was a notable decline in use of BSP by $64 \%$ during the second week, which may be attributable to participants' lack of motivation associated with the end of the semester, but rates of BSP remained 240\% higher than during baseline. Interpretation of these group-level analyses are tempered with the individual-level of analysis which demonstrated that 8 of 13 participants increased their use of BSP, with two using less BSP during post-intervention, and one participant who didn't use BSP during any of the study's observations. Post-presentation survey results suggest that the instructional presentation was generally useful, informative, and somewhat enjoyable. Post-study survey results suggested that BSP and the use of self-monitoring were generally acceptable and that participants on average endorsed their use for preschool teachers. Implications and limitations for these results are discussed below.

Altogether, the current study adds to the literature on professional development for improving early educators' use of evidence-based practices in multiple ways. This study provided evidence that a structural quality change (the training package) was capable of producing a change in process quality (improving educators' use of self-monitoring to increase 
INSTRUCTIONAL PACKAGE TO PROMOTE BEHAVIOR-SPECIFIC PRAISE 43

their use BSP of while interacting with the children). Furthermore, this structural quality change was effective without the need for instruction or feedback from an expert for most of the participants, and data were collected without participants being explicitly aware of which of their teaching behaviors were of being observed By removing the need for an expert, this training package could be made available to a wide range of early education centers that do not have the funds nor the geographic proximity to access high-quality training. Developing effective training packages that can be widely accessible was recently called for in a review of the praise research and has been highlighted in reviews on associations between professional development and improving the process quality provided by early educators (Early et al., 2007; Floress, Beschta, Meyer, \& Reinke, 2017). Teaching educators how to use self-monitoring to improve their use of evidence-based practices may be one of the solutions to making high-quality early education more accessible.

This study may also be the only study on BSP in which participants were not directly made aware of the researchers' intent. That is, the researchers told participants that their "general teaching practices" were being observed for both phases of the study, without explicitly mentioning BSP or self-monitoring. This lends to the external validity of this training protocol to be used in settings where educators would not be observed regularly for their use of BSP.

The two primary methods used to remove the need for an expert trainer were the use of self-monitoring to provide feedback to participants, and a pre-recorded instructional presentation that provided all initial instruction for how and why to use BSP and self-monitoring. Participants rated the presentation on average as satisfying, helpful in learning how to use self-monitoring and BSP, somewhat boring, and somewhat interesting. Production quality of the presentation could have contributed to its being rated as only somewhat interesting and somewhat boring - 
INSTRUCTIONAL PACKAGE TO PROMOTE BEHAVIOR-SPECIFIC PRAISE 44

there were no animated scenes, only a few images, and the slides primarily consisted of text with voice-over narration. Despite the low production quality, it received generally high ratings for its contribution towards helping participants learn how to use BSP, and how to self-monitor their use of BSP while they teach. Other iterations of an instructional presentation could try using a higher production quality with more images and perhaps some presentations to increase participants' interest.

This study also adds to the pool of research that shows educators tend to give high ratings of satisfaction for use of self-monitoring and BSP (for a review, see Floress et al., 2017). Participants' ratings of acceptability are important to highlight because there is evidence that educators will more quickly adopt and while in the absence of coaching, maintain new teaching practices for longer when those teaching practices are preferred (Johnson et al., 2014). On average, participants liked to use, thought they were effective, and would recommend selfmonitoring and BSP to other educators. However, there were some findings that suggest selfmonitoring would not be the preferred choice for all teachers - one participant rated all items of the post-study survey as 1 (Strongly Disagree), and although this person's responses were excluded from analyses due to their rating the reverse-coded items the same as the non-reversedcoded items, it may be that their distaste for the training package led them to give multiple genuine poor ratings, without realizing they were inadvertently also giving a favorable rating to some questions. Additionally, only three of the nine participants who completed the post-study survey reported not experiencing discomfort while using self-monitoring. Three either somewhat or strongly agreed that it caused them discomfort, and two others neither agreeing nor disagreeing. One participant that reported feeling some discomfort also reported that the children they worked with also experienced discomfort due to the self-monitoring. Conceptually, self- 
INSTRUCTIONAL PACKAGE TO PROMOTE BEHAVIOR-SPECIFIC PRAISE 45

monitoring is seen as the vehicle for promoting the use of BSP, however not all participants rated BSP positively. One participant indicated that they did not like using BSP, although they indicated that they would be willing to continue using and would recommend others to use BSP. Follow-up interviews would have been helpful in determining why some participants did not like self-monitoring and BSP, while others did. Effective training packages designed to be disseminated and accessible must also be palatable. Research on expanding the accessibility of effective training packages should include assessments of educators' perceived acceptability, ease of use, and likelihood to continue or recommend use for others.

\section{Limitations}

While results were promising, they demonstrate just the early stages of the assessment and development of a training package that could have wide-spread application. Some important limitations should be recognized and used to guide future research. First, not all participants improved their use of BSP. Four participants used BSP less often during the post-intervention phase than baseline, and one participant never used BSP across both phases. While the average increase in use of BSP was significant, it would be inappropriate to overlook those participants whose use of BSP worsened or had no change. This is a limitation not of the methodology of this

study per se, but rather of the effectiveness of the training package implemented. Future research should examine ways to improve upon the effectiveness of the training package. One possible approach would be to emphasize learning to distinguish between general praise and BSP during the instructional presentation. During observations, many participants were seen adding counts to their golf counter after they provided general praise statements, even though they were instructed to only track their use of BSP. Differentiating between GP and BSP could be facilitated by providing participants with a brief online task where they must sort different praise statements 
INSTRUCTIONAL PACKAGE TO PROMOTE BEHAVIOR-SPECIFIC PRAISE 46

into general or BSP categories and are provided feedback on their accuracy as well as

explanations for any errors made. One important methodological limitation of this study was the lack of ability to link participants' survey responses to their behavior change. Participants were allowed to complete all survey items anonymously, and none of their responses could be linked to performance in the classroom. Future studies should attempt to link participant responses to endorsement and satisfaction of the instructional package to their actual behavior within the classroom.

A second limitation of this study was that all of its participants were selected from a population of convenience, and participants were generally homogenous on age and education. Results of both the effectiveness and acceptability of the training package should not be expected to be precisely replicated in other populations. The setting of this study was also unique in that it took place at a university's nursery school, whose director regularly engages in on-site research projects, and may be more motivated and accepting of the materials than directors at other centers. It may be that other less motivated early educators with a less-motivated director may not adhere to the protocols outlined in the training package's handbooks nor the instructional presentation, thereby producing less effective results. Finally, the population of convenience also limited the methodological structure of the study to a within-participants comparison. Use of the pre-post design was determined to be the most appropriate for this population and this behavior for two reasons. First, this population frequently interacted together, and frequently taught in very close proximity to one another within the same classroom. Attempting to run a single-case design such as a multiple baseline or $\mathrm{ABAB}$ withdrawal would not have been ideal due to the high potential of the diffusion of treatment between participants (Shadish, Cook, \& Campbell, 2002). Second, BSP has been shown to be very resistant to change without direct feedback. 
INSTRUCTIONAL PACKAGE TO PROMOTE BEHAVIOR-SPECIFIC PRAISE 47

Meaning, the threat of extra-experimental history effects on the pre-post design would be unlikely to result in a change in participants' use of BSP unless they were receiving explicit feedback on their use of BSP from somewhere outside of the study, and that feedback would need to have coincided with the post-intervention phase of this study, a highly improbable turn of events. Future research using this type of training package should include populations of early childhood educators that reflect broader contexts of education, age, and prior training, in order to determine the limitations and needed adaptations to make such a training package as accessible and effective as possible.

A third and fourth limitation comes from analyzing the post-intervention phase data. It is important to note that there were distinct changes in the rates of BSP between the first and second weeks during the post-intervention phase, and that observations during post-intervention spanned only a two-week timespan. The change in rates of BSP suggests that motivational influences will have a large impact on the training package's effectiveness. During the second week post-intervention, participants reduced their use of BSP by $36 \%$ of the first week postintervention. It is unknown whether the rates of BSP would have continued to drop had observations been able to continue for a longer period. It could also be the case that the drop in rate was due exclusively to motivational variables regarding being "checked out" of school, as participants reported they were ready to receive their grades and for the semester to end. However, because all participants were on the same time schedule, it is impossible to determine what caused the drop in BSP - an unmotivating procedure, a context of demotivation brought on by the end of the semester, a mixture of both, or some other unknown variable. Future research should focus on how long the changes in teachers' behaviors are maintained. It is not unreasonable to include in the standards of judgement for professional development training 
INSTRUCTIONAL PACKAGE TO PROMOTE BEHAVIOR-SPECIFIC PRAISE 48

packages an emphasis that behavior change lasts long enough to have a positive effect on teaching quality and child outcomes. Therefore, future research should include measures of teacher motivation to adhere to the training package, and should also include a methodology that allows for longitudinal behavior-change monitoring. It is not known how long the observed increases in BSP would last, but it is an important question to answer if our goal as researchers is to improve teaching quality for the long-term.

A fifth and final limitation that may be levied against the experimental evaluation of this study is that there was no control group, nor random assignment to conditions. Although it may be possible that an extra-experimental influence could have contributed to the results seen, it is unlikely that any extra-experimental influence would have a significant impact. This conclusion is derived from the dozens of studies that have shown that the only known effective way to increase use of BSP is through providing direct feedback on one's use of BSP (Cavanaugh, 2013). The Director of the center reported giving no feedback to the participants regarding their use of BSP, and no external feedback was observed by the researchers. Arguments for other extra-experimental influences such as maturation effects are equally unlikely the cause of any improvements in BSP following the same logic as described above. Pre-Post designs are appropriate for studying behavior that is known to be relatively stable (Shadish, Cook, \& Campbell, 2002). Had participants received some other exposure to using BSP outside of the instructional package, that exposure would have necessitated feedback on their use of BSP in some form - which does not regularly occur and would have been very unlikely to occur only during the post-intervention phase of this study, and not during baseline. Given these arguments, the limitation of this quasi-experimental design's ability to rule out all extra-experimental influences is considered a minor limitation and does not change the conclusions drawn regarding 
INSTRUCTIONAL PACKAGE TO PROMOTE BEHAVIOR-SPECIFIC PRAISE 49

the effectiveness of the instructional package to produce improvements in self-monitoring and BSP.

\section{Future Directions}

In addition to those mentioned above (i.e., expand the populations, assess behavior change over a longer period of time, etc.), future studies should assess the qualities of selfmonitoring that make it aversive to some participants. These assessments could compare procedural differences, such as that done by Simonsen and colleagues (2013), in which different modes of self-monitoring could be compared for preference and effectiveness, and educators could be given a choice to use their most preferred method. The research methodology could also be extended to include qualitative data collection and analyses such as focus groups or interviews to determine which elements of self-monitoring are aversive. It may be that simply having another thing to think about in an already somewhat chaotic environment adds to already existing stress, or it may be that participants don't understand the need for self-monitoring, and therefore feel it may be an unnecessary burden. All participants indicated that they thought other preschool teachers both should and would use BSP. However, while all participants indicated that they thought other preschool teachers should use self-monitoring, one participant indicated that they were unsure of if other preschool teachers would use self-monitoring. If self-monitoring is to be a vehicle that delivers needed feedback for improving teaching behaviors, it will need to be implemented in such a way that is appetitive to the users.

Although BSP was the target behavioral kernel (Embry \& Biglan, 2008) of this study, it is not the only evidence-based teaching practice that is widely recommended to educators. Other candidate targets could be the use of prompts to guide appropriate social interactions between children, the use of opportunities to respond, planned ignoring of non-dangerous inappropriate 
INSTRUCTIONAL PACKAGE TO PROMOTE BEHAVIOR-SPECIFIC PRAISE 50

behavior, and rule reminders (Hester et al., 2009; Simonsen, DeLuca, \& Myers, 2010; Simonsen, Myers, \& DeLuca, 2010). A brief instructional package that uses self-monitoring to drive behavior change could be modified to target a suite of evidence-based practices and could theoretically be utilized by any early educator with access to the internet. The cost to the early educator would be minimal, and potentially limited to only the purchase of golf counters (or other preferred self-monitoring device; many golf counters can be purchased for under \$5). In this way, effective professional development training and therefore high quality early education could be made accessible to a much broader community. 
INSTRUCTIONAL PACKAGE TO PROMOTE BEHAVIOR-SPECIFIC PRAISE 51

\section{References}

Barnett, W. S. (2004). Better teachers, better preschools: Student achievement linked to teacher qualifications. Preschool Policy Matters, 2, 1-12.

Barnett, W. S. (2008). Preschool education and its lasting effects: Research and policy implications. Boulder and Tempe: Education and the Public Interest Center \& Education Policy Research Unit. Retrieved from: http://epicpolicy.org/pbulications/preschool$\underline{\text { education }}$

Barnett, W. S. (2011). Effectiveness of early educational intervention. Science, 333, 975-978. doi: 10.1126/science.1204534

Biglan, A. (2015). The Nurture Effect: How the Science of Human Behavior Can Improve Our Lives \& Our World. Oakland, CA: New Harbinger Publications.

Binder, C., \& Watkins, C. L. (2013). Precision teaching and Direct Instruction: Measurably superior instructional technology in schools. Performance Improvement Quarterly, 3(4), 74-96. doi: 10.1111/j.1937-8237.1990.tb00478.x

Brophy, J. (1981). Teacher praise: A functional analysis. Review of Educational Research, 51(1), $5-32$.

Cameron, J., \& Pierce, D. (1994). Reinforcement, reward, and intrinsic motivation: A metaanalysis. Review of Educational Research, 64(3), 363-423.

Cameron, J., Banko, K. M., \& Pierce, W. D. (2001). Pervasive negative effects of rewards on intrinsic motivation: The myth continues. The Behavior Analyst, 24(1), 1-44.

Cavanaugh, B. (2013). Performance feedback and teachers' use of praise and opportunities to respond: A review of the literature. Education and Treatment of Children, 36(1), 111136. doi: 10.1353/etc.2013.0001 
INSTRUCTIONAL PACKAGE TO PROMOTE BEHAVIOR-SPECIFIC PRAISE 52

Chorpita, B. F., \& Daleiden, E. L. (2009). Mapping evidence-based treatments for children and adolescents: Application of the distillation and matching model to 615 treatments from 322 randomized trials. Journal of Consulting and Clinical Psychology, 77(3), 566-579.

Codding, R. S., Livanis, A., Pace, G. M., \& Cava, L. (2008). Using performance feedback to improve treatment integrity of classwide behavior plans: An investigation of observer reactivity. Journal of Applied Behavior Analysis, 41, 417-422. doi: 10.1901/jaba.2008.4147.

Connell, S., Sanders, M. R., \& Markie-Dadds, C. (1997). Self-directed behavioral family intervention for parents of oppositional children in rural and remote areas. Behavior Modification, 21(4), 379-408.

Conroy, M. A., Sutherland, K. S., Vo, A. K., Carr, S., \& Ogston, P. L. (2014). Early childhood teachers' use of effective instructional practices and the collateral effects on young children's behavior. Journal of Positive Behavior Interventions, 16(2), 81-92. doi: $10.1177 / 1098300713478666$

Cooper, J. O., Heron, T. E., \& Heward, W. L. (2014). Applied behavior analysis. Edinburgh gate: Pearson educational international.

Deci, E. L., Koestner, R., \& Ryan, R. M. (1999). A meta-analytic review of experiments examining the effects of extrinsic rewards on intrinsic motivation. Psychological Bulletin, 125(6), 627-668.

Duchaine, E. L., Jolivette, K., \& Fredrick, L. D. (2011). The effect of teacher coaching with performance feedback on behavior-specific praise in inclusion classrooms. Education and Treatment of Children, 34(2), 209-227. Doi: 10.1353/etc.2011.0009 
INSTRUCTIONAL PACKAGE TO PROMOTE BEHAVIOR-SPECIFIC PRAISE 53

Early, D. M., Bryant, D. M., Pianta, R. C., Clifford, R. M., Burchinal, M. R., Ritchie, S., ..., \& Barbarin, O. (2006). Are teachers' education, major, and credentials related to classroom quality and children's academic gains in pre-kindergarten? Early Childhood Research Quarterly, 21, 174-195. Doi:10.1016/j.ecresq.2006.04.004

Early, D., Maxwell, K., Burchinal, M., Alva, S., Bender, R., Bryant, D., . . Zill, N. (2007). Teachers' education, classroom quality, and young children's academic skills: Results from seven studies of preschool programs. Child Development, 78(2), 558-580.

Embry, D. D., \& Biglan, A. (2008). Evidence-based kernels: Fundamental units of behavioral influence. Clinical Child and Family Psychology Review, 11(3), 75-113. Doi: 10.1007/s10567-008-0036-X

Embry, D. Staatmeier, G., Richardson, C., Lauger, K., \& Mitich, J. (2003). The PAX Good Behavior Game ( $1^{\text {st }}$ ed). Center City: Hazelden.

Fullerton, E. K., Conroy, M. A., \& Correa, V. I. (2009). Early childhood teachers' use of specific praise statements with young children at risk for behavioral disorders. Behavioral Disorders, 34(3), 118-135.

Gable, R. A., Hester, P. H., Rock, M. L., \& Hughes, K. G. (2009). Back to basics: Rules, praise, ignoring, and reprimands revisited. Intervention in School and Clinic, 44(4), 195-205. doi: $10.1177 / 1053451208328831$

Garland, A. F., Hawley, K. M., Brookman-Frazee, L., \& Hurlburt, M. S. (2008). Identifying common elements of evidence-based psychosocial treatments for children's disruptive behavior problems. Journal of the American Academy of Child and Adolescent Psychiatry, 47(5), 505-514. Doi: 10.1097/CHI.0b013e31816765c2 
INSTRUCTIONAL PACKAGE TO PROMOTE BEHAVIOR-SPECIFIC PRAISE 54

Hager, K. D. (2012). Self-monitoring as a strategy to increase student teachers' use of effective teaching practices. Rural Special Education Quarterly, 31(4), 9-17.

Hancock, D. R. (2002). Influencing graduate students' classroom achievement, homework habits and motivation to learn with verbal praise. Educational Research, 44(1), 83-95. doi: $10.1080 / 00131880110107379$

Hanley, G. P., Fahmie, T. A., \& Heal, N. A. (2014). Evaluation of the preschool life skills program in head start classrooms: A systematic replication. Journal of Applied Behavior Analysis, 47(2), 443-448. Doi: 10.1002/jaba.132

Hester, P. P., Hendrickson, J. M., \& Gable, R. A. (2009). Forty year later - The value of praise, ignoring, and rules for preschoolers at risk for behavior disorders. Education and Treatment of Children, 32(4), 513-535.

Isaacs, J. B. (2008). Impacts of early childhood programs. Retrieved from Brookings Institute Website: https://www.brookings.edu/wpcontent/uploads/2016/06/09_early_programs_isaacs.pdf

Ishimine, K., \& Tayler, C. (2014). Assessing quality in early childhood education and care. European Journal of Education Research, Development and Policy, 49(2), 272-290. https://doi.org/10/1111/ejed.12043

Jenkins, L. N., Floress, M. T., \& Reinke, W. (2015). Rates and types of teacher praise: A review and future directions. Psychology in the Schools, 52(5), 463-476. doi: 10.1002/pits.21835

Jennings, J. L., \& Diprete, T. A. (2010). Teacher effects on social and behavioral skills in early elementary school. Sociology of Education, 83(2), 135-159. doi: $10.1177 / 0038040710368011$ 
INSTRUCTIONAL PACKAGE TO PROMOTE BEHAVIOR-SPECIFIC PRAISE 55

Johnson, L. D., Wehby, J. H., Symons, F. J., Moore, T. C., Maggin, D. M., \& Sutherland, K. S. (2014). An analysis of preference relative to teacher implementation of intervention. The Journal of Special Education, 48(3), 214-224. Doi: 10.1177/0022566913475872

Kalis, T. M., Vannest, K. J., \& Parker, R. (2007). Praise counts: Using self-monitoring to increase effective teaching practices. Preventing School Failure, 51(3), 20-27.

Kohn, A. (1993). Punished by rewards. Boston: Houghton-Mifflin.

Kratochwill, T. R., Hitchcock, J., Horner, R. H., Levin, J. R., Odom, S. L., Rindskopf, D. M. \& Shadish, W. R. (2010). Single-case designs technical documentation. Retrieved from What Works Clearinghouse website: http://ies.ed.gov/ncee/wwc/pdf/wwc_scd.pdf.

Mashburn, A. J. (2008). Quality of social and physical environments in preschools and children's development of academic, language, and literacy skills. Applied Developmental Science, 12(3), 113-127. Doi: 10.1080/10888690802199392

McLeod, B. D., Sutherland, K. S., Martinez, R. G., Conroy, M. A., Snyder, P. A., \& SouthamGerow, M. A. (2016). Identifying common practice elements to improve social, emotional, and behavioral outcomes of young children in early childhood classrooms. Prevention Science. doi: 10.1007/s11121-016-0703-y

Miles, M. B., Huberman, A. M., \& Saldaña, J. (2014). Qualitative data analysis a methods sourcebook $\left(3^{\text {rd }} e d\right)$. Thousand Oaks, CA: Sage Publications, Inc.

Myers, R. B. (2004). In search of quality in programmes in early childhood care and education. Paper commissioned for the Education for All Global Monitoring Report 2005: The Quality Imperative. United Nations Educational, Scientific and Cultural Organization, Paris. Retrieved from UNESCO website: http://unesdoc.unesco.org/images/0014/001474/147473e.pdf 
INSTRUCTIONAL PACKAGE TO PROMOTE BEHAVIOR-SPECIFIC PRAISE 56

NCQTL National Center on Quality Teaching and Learning. (2013). Improving teacher-child interactions: Using the CLASS in Head Start preschool programs. Seattle, WA: Norris and Dorothy Haring Center for Applied Research and Training in Inclusive Education.

NICHD Early Child Care Research Network. (2002). Child care structure > Process>Outcome: Direct and Indirect effects of child care quality on young children's development. Psychological Science, 13, 199-206.

Oliver, R. M., Wehby, J. H., \& Nelson, J. R. (2015). Helping teachers maintain classroom management practices using a self-monitoring checklist. Teaching and Teacher Education, 51, 113-120. http://dx.doi.org/10.1016/j.tate.2015.06.007

Pisacreta, J., Tincani, M., Connell, J. E., \& Axelrod, S. (2011). Increasing teachers' use of a 1:1 praise-to-behavior correction ratio to decrease student disruption in general education classrooms. Behavioral Interventions, 26, 243-260. doi: 10.1002/bin.341

Rathel, J. M., Drasgow, E., \& Christle, C. C. (2008). Effects of supervisor performance feedback on increasing preservice teachers' positive communication behaviors with students with emotional and behavioral disorders. 16(2), 67-77. 10.1177/1063426607312537

Reimers, T., \& Wacker, D. P. (1988). Parents' ratings of acceptability of behavioral treatment recommendations made in an outpatient clinic: A preliminary analysis of the influence of treatment effectiveness. Behavioral Disorders, 14, 7-15.

Shadish, W. R., Cook, T. D., \& Campbell, D. T. (2002). Experimental and quasi-experimental designs for generalized causal inference. Boston, MA, US: Houghton, Mifflin and Company. 
INSTRUCTIONAL PACKAGE TO PROMOTE BEHAVIOR-SPECIFIC PRAISE 57

Simonsen, B., Myers, D., \& DeLuca, C. (2010). Teaching teachers to use prompts, opportunities to respond, and specific praise. Teacher Education and Special Education, 33(4), 300318. Doi: $10.1177 / 0888406409359905$

Simonsen, B., MacSuga, A. S., Fallon, L. M., \& Sugai, G. (2013). The effects of self-monitoring on teachers' use of specific praise. Journal of Positive Behavior Interventions, 15(1), 515. doi:10.1177/1098300712440543

Sloat, K., Tharp, R., Gallimore, R. (1977). The incremental effectiveness of classroom-based teacher-training techniques. Behavior Therapy, 8, 810-818.

St. Peter, C. C., Brunson, L. Y., Cook, J. E., Subramaniam, S., Larson, N. A., Clingan, M., \& Poe, S. G. (2014). Adherence to discrete-trial instruction procedures by rural parents of children with autism. Behavioral Interventions, 29(3), 200-212. Doi: 10.1002/bin.1386

Subramaniam, S., Brunson, L. Y., Cook, J. E., Larson, N. A., Poe, S. G., \& St. Peter, C. C. (2017). Maintenance of parent-implemented discrete-trial instruction during videoconferencing. Journal of Behavioral Education, 26(1), 1-26. Doi: 10.1007/s10864016-9258-z

Sutherland, K. S., Copeland, S., \& Wehby, J. H. (2001). Catch them while you can: Monitoring and increasing the use of effective praise. Council for Exceptional Children, 11(1), 46-49.

Sutherland, K. S., \& Wehby, J. H. (2001). The effect of self-evaluation on teaching behavior in classrooms for students with emotional and behavioral disorders. The Journal of Special Education, 35(3), 161-171.

Sutherland, K. S., Wehby, J. H., \& Copeland, S. (2000). Effect of varying rates of behaviorspecific praise on the on-task behavior of students with EBD. Journal of Emotional and Behavioral Disorders, 8(1), 2-8. 
INSTRUCTIONAL PACKAGE TO PROMOTE BEHAVIOR-SPECIFIC PRAISE 58

Taber, K. S. (2017). The Use of Cronbach's Alpha When Developing and Reporting Research Instruments in Science Education. Research in Science Education. https://doi.org/10.1007/s11165-016-9602-2

Tingstrom, D. H., Sterling-Turner, H. E., \& Wilczynski, S. M. (2006). The Good Behavior Game: 1969-2002. Behavior Modification, 30(2), 225-253. doi: $10.1177 / 0145445503261165$

Vandell, D. L., Belsky, J., Buchinal, M., Vandergrift, N., \& Steinberg, L. (2010). Do effects of early child care extend to age 15 years? Results from the NICHD study of early child care and youth development. Child Development, 81(3), 737-756. Doi: 10.1111/j.14678624.2010.01431.x

Ward-Horner, J., \& Sturmey, P. (2012). Component analysis of behavioral skills training in functional analysis. Behavioral Interventions, 27, 75-92. doi: 10.1002/bin.1339 
INSTRUCTIONAL PACKAGE TO PROMOTE BEHAVIOR-SPECIFIC PRAISE 59

Table 1.

Results for Null Multilevel Model

\begin{tabular}{lccc}
\hline & Coefficient & $S E$ & $d f$ \\
\cline { 2 - 4 } Intercept $\left(\gamma_{00}\right)$ & $0.81^{*}$ & 0.19 & 12 \\
$\sigma^{2}$ & 1.35 & 0.15 & - \\
$\tau$ & & & - \\
\hline
\end{tabular}

$* p<.001$ 
INSTRUCTIONAL PACKAGE TO PROMOTE BEHAVIOR-SPECIFIC PRAISE 60

Table 2.

Coding Scheme for Slopes-As-Intercepts Variables

Variable dummy code

$\underline{\text { PostWeek1 }}$

PostWeek2

Pre-treatment phase

0

0

First week following instructional

1

0

presentation

Second week following instructional

1

1

presentation 
INSTRUCTIONAL PACKAGE TO PROMOTE BEHAVIOR-SPECIFIC PRAISE 61

Table 3.

Results for Piecewise Model

Coefficient $\quad S E \quad d f$

Intercept $\left(\gamma_{00}\right)$

$0.56^{*}$

0.19

12

PostWeek1 slope $\left(\gamma_{10}\right)$

$1.60^{* * *}$

0.40

164

PostWeek2 slope $\left(\gamma_{20}\right)$

$-0.77 * *$

0.27

164

$* p<.05 .{ }^{* *} p<.001$ 
INSTRUCTIONAL PACKAGE TO PROMOTE BEHAVIOR-SPECIFIC PRAISE 62

Table 4.

Means, Standard Deviations, and Response Distribution for Post-Presentation Items Related to Participants' Satisfaction With the Instructional Presentation

\begin{tabular}{lcccccc}
\hline & $\begin{array}{l}\text { Mean (SD) } \\
n=10\end{array}$ & $\begin{array}{c}\text { Strongly } \\
\text { Disagree }\end{array}$ & $\begin{array}{c}\text { Somewhat } \\
\text { Disagree }\end{array}$ & $\begin{array}{c}\text { Neither } \\
\text { Agree nor } \\
\text { Disagree }\end{array}$ & $\begin{array}{c}\text { Somewhat } \\
\text { Agree }\end{array}$ & $\begin{array}{c}\text { Strongly } \\
\text { Agree }\end{array}$ \\
\hline Overall & $4.40(.70)$ & 0 & 0 & 1 & 4 & 5 \\
Satisfaction & & & & & 3 & 3 \\
Interesting & $3.70(1.25)$ & 1 & 0 & 3 & 3 & 1 \\
Boring & $2.70(1.42)$ & 3 & 1 & 3 & 2 & \\
\hline
\end{tabular}


INSTRUCTIONAL PACKAGE TO PROMOTE BEHAVIOR-SPECIFIC PRAISE 63

Table 5.

Means, Standard Deviations, and Response Distribution for Post-Presentation Items Related to Participants' Knowledge Gain of BSP from the Instructional Presentation

\begin{tabular}{llccccc}
\hline & $\begin{array}{l}\text { Mean } \\
(\mathrm{SD}) \\
n=10\end{array}$ & $\begin{array}{c}\text { Strongly } \\
\text { Disagree }\end{array}$ & $\begin{array}{c}\text { Somewhat } \\
\text { Disagree }\end{array}$ & $\begin{array}{c}\text { Neither } \\
\text { Agree nor } \\
\text { Disagree }\end{array}$ & $\begin{array}{c}\text { Somewhat } \\
\text { Agree }\end{array}$ & $\begin{array}{c}\text { Strongly } \\
\text { Agree }\end{array}$ \\
\hline $\begin{array}{c}\text { Didn't know much about } \\
\text { BSP before }\end{array}$ & $\begin{array}{l}2.90(1.00) \\
\text { Easy to understand BSP }\end{array}$ & 1 & 3 & 2 & 4 & 0 \\
Helped understanding of & $4.60(.52)$ & 0 & 0 & 0 & 4 & 6 \\
BSP & $4.20(.63)$ & 0 & 0 & 1 & 6 & 3 \\
How to Use BSP & $4.30(.67)$ & 0 & 0 & 1 & 5 & 4 \\
How to use self- & $4.50(.53)$ & 0 & 0 & 0 & 5 & 5 \\
monitoring & & & & & & \\
\end{tabular}


INSTRUCTIONAL PACKAGE TO PROMOTE BEHAVIOR-SPECIFIC PRAISE 64

Table 6.

Means, Standard Deviations, and Response Distribution for Post-Study Satisfaction Items

Related to Ease of Implementation of Self-Monitoring

\begin{tabular}{lcccccc}
\hline & $\begin{array}{c}\text { Mean (SD) } \\
N=9\end{array}$ & $\begin{array}{c}\text { Strongly } \\
\text { Disagree }\end{array}$ & $\begin{array}{c}\text { Somewhat } \\
\text { Disagree }\end{array}$ & $\begin{array}{c}\text { Neither } \\
\text { Agree nor } \\
\text { Disagree }\end{array}$ & $\begin{array}{c}\text { Somewhat } \\
\text { Agree }\end{array}$ & $\begin{array}{c}\text { Strongly } \\
\text { Agree }\end{array}$ \\
\hline Easy to use & $3.89(1.17)$ & 1 & 0 & 0 & 6 & 2 \\
Worth the effort & $4.22(.97)$ & 0 & 1 & 0 & 4 & 4 \\
Discomfort & $2.67(1.50)$ & 3 & 1 & 1 & 2 & 1 \\
Disadvantages & $2.77(.97)$ & 1 & 2 & 4 & 2 & 0 \\
\hline
\end{tabular}


INSTRUCTIONAL PACKAGE TO PROMOTE BEHAVIOR-SPECIFIC PRAISE 65

Table 7.

Means, Standard Deviations, and Response Distribution for Post-Study Satisfaction Items

Related to Perceived Effects of Self-Monitoring

\begin{tabular}{lcccccc}
\hline & $\begin{array}{c}\text { Mean (SD) } \\
N=9\end{array}$ & $\begin{array}{c}\text { Strongly } \\
\text { Disagree }\end{array}$ & $\begin{array}{c}\text { Somewhat } \\
\text { Disagree }\end{array}$ & $\begin{array}{c}\text { Neither } \\
\text { Agree nor } \\
\text { Disagree }\end{array}$ & $\begin{array}{c}\text { Somewhat } \\
\text { Agree }\end{array}$ & $\begin{array}{c}\text { Strongly } \\
\text { Agree }\end{array}$ \\
\hline Children discomfort & $2.11(1.67)$ & 4 & 1 & 3 & 1 & 0 \\
Teacher discomfort & $2.67(1.5)$ & 3 & 1 & 2 & 2 & 1 \\
Undesirable effects & $2.44(.88)$ & 1 & 4 & 3 & 1 & 0 \\
$\quad \begin{array}{c}\text { on teaching } \\
\text { Positive impact on }\end{array}$ & $3.67(.87)$ & 0 & 0 & 5 & 2 & 2 \\
teaching & & & & & & \\
\hline
\end{tabular}


INSTRUCTIONAL PACKAGE TO PROMOTE BEHAVIOR-SPECIFIC PRAISE 66

Table 8. Means, standard deviations, and response distribution for post-study satisfaction items related to endorsing the use of self-monitoring BSP.

\begin{tabular}{|c|c|c|c|c|c|c|}
\hline & $\begin{array}{c}\text { Mean (SD) } \\
N=9\end{array}$ & $\begin{array}{l}\text { Strongly } \\
\text { Disagree }\end{array}$ & $\begin{array}{l}\text { Somewhat } \\
\text { Disagree }\end{array}$ & $\begin{array}{c}\text { Neither } \\
\text { Agree nor } \\
\text { Disagree }\end{array}$ & $\begin{array}{c}\text { Somewhat } \\
\text { Agree }\end{array}$ & $\begin{array}{c}\text { Strongly } \\
\text { Agree }\end{array}$ \\
\hline Liked using BSP & $4.33(1.00)$ & 0 & 1 & 0 & 3 & 5 \\
\hline Liked using self- & $4.22(.44)$ & 0 & 0 & 0 & 7 & 2 \\
\hline \multicolumn{7}{|l|}{ monitoring } \\
\hline Willing to use BSP & $4.77(.44)$ & 0 & 0 & 0 & 2 & 7 \\
\hline \multicolumn{7}{|l|}{ in future } \\
\hline Willing to use self- & $4.67(.50)$ & 0 & 0 & 0 & 3 & 6 \\
\hline \multicolumn{7}{|l|}{ monitoring in } \\
\hline \multicolumn{7}{|l|}{ future } \\
\hline Others would use & $4.67(.50)$ & 0 & 0 & 0 & 3 & 6 \\
\hline \multicolumn{7}{|l|}{$\mathrm{BSP}$} \\
\hline Others would use & $4.22(.83)$ & 0 & 0 & 2 & 3 & 4 \\
\hline \multicolumn{7}{|l|}{ self-monitoring } \\
\hline Would recommend & $4.78(.44)$ & 0 & 0 & 0 & 2 & 7 \\
\hline \multicolumn{7}{|l|}{ BSP to others } \\
\hline Would recommend & $4.44(.73)$ & 0 & 0 & 1 & 3 & 5 \\
\hline \multicolumn{7}{|l|}{ self-monitoring } \\
\hline to others & & & & & & \\
\hline
\end{tabular}


INSTRUCTIONAL PACKAGE TO PROMOTE BEHAVIOR-SPECIFIC PRAISE 67

\section{Average BSP Use Per Minute}

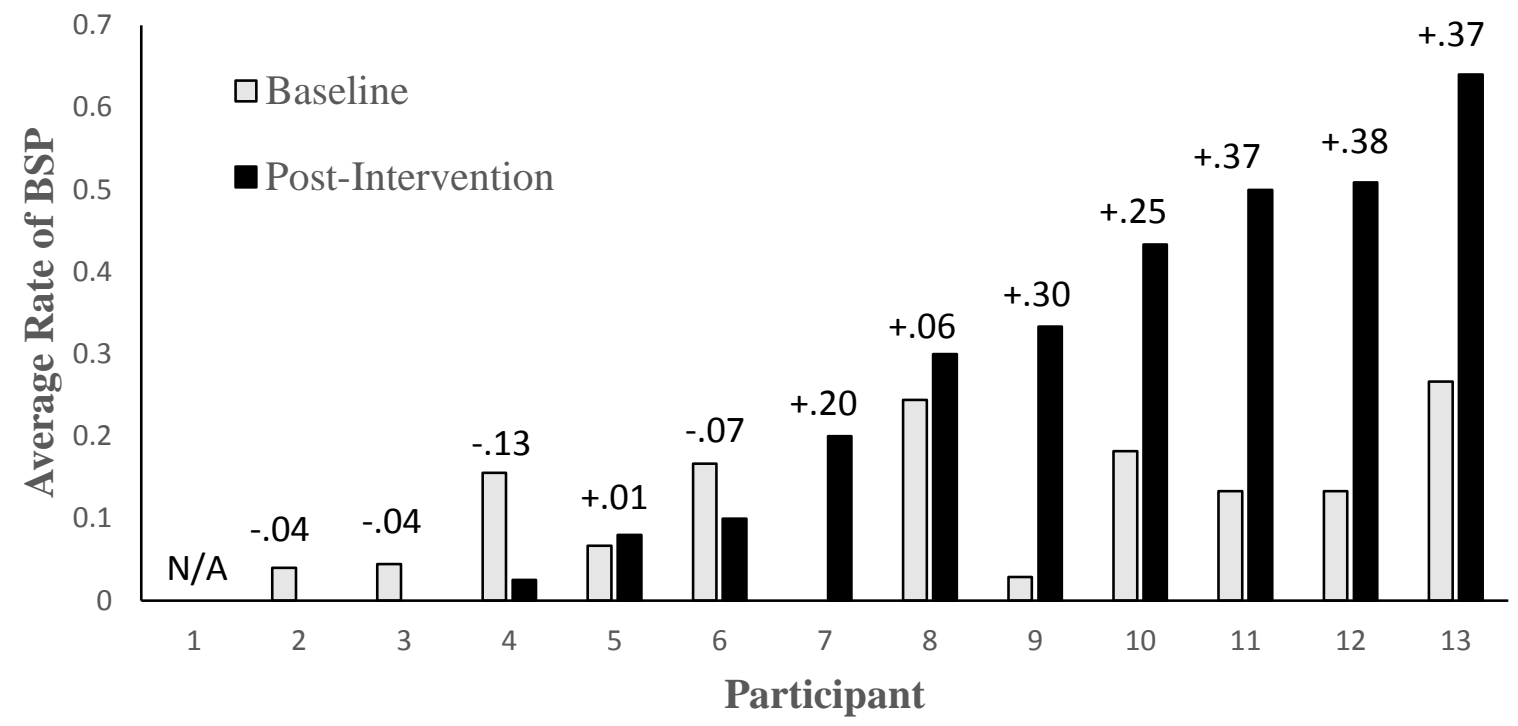

Figure 1. Total use of BSP during baseline and post-intervention phases, for each participant. 


\section{Appendix A}

Teacher Obs'd:

\section{BSP Data Collection Sheet}

Teaching Activity:

Session Numbers:

Session Date:

Time of Session:

\section{Operational Definitions}

Observer's Name:

BSpecificP: Any audible, specific, and positive verbal feedback to one or more students contingent on behavior, and describes the behavior being praised.

GeneralP: Any praise statement that meets the definition for a BSP but does not specify the behavior being praised. Multiple BSP or GPs to be counted within a 5-s window, the new BSP must specify either a new specific behavior, or be directed to a different child

Self-monitoring Anytime a teacher is observed using a hand-held counter during a session

\begin{tabular}{|c|c|c|c|c|c|c|}
\hline Bin \# and Time & BSpecificP & GeneralP & $\begin{array}{l}\text { Total } \\
\text { \# BSP }\end{array}$ & $\begin{array}{l}\text { Bin } \\
\text { IOA \% }\end{array}$ & $\begin{array}{l}\text { Total } \\
\text { \# GP }\end{array}$ & $\begin{array}{l}\text { Bin } \\
\text { IOA \% }\end{array}$ \\
\hline \multicolumn{7}{|l|}{ Bin $1(: 00-: 29)$} \\
\hline \multicolumn{7}{|l|}{ Bin $2(30-59)$} \\
\hline \multicolumn{7}{|l|}{ Bin $3(1: 00-1: 29)$} \\
\hline \multicolumn{7}{|l|}{ Bin $4(1: 30-1: 59)$} \\
\hline \multicolumn{7}{|l|}{ Bin 5 (2:00-2:29) } \\
\hline \multicolumn{7}{|l|}{ Bin $6(2: 30-2: 59)$} \\
\hline \multicolumn{7}{|l|}{ Bin $7(3: 00-3: 29)$} \\
\hline \multicolumn{7}{|l|}{ Bin $8(3: 30-3: 59)$} \\
\hline \multicolumn{7}{|l|}{ Bin $9(4: 00-4: 29)$} \\
\hline \multicolumn{7}{|l|}{ Bin $10(4: 30-4: 59)$} \\
\hline \multicolumn{7}{|c|}{ Use Self-monitoring? Yes / No } \\
\hline Bin \# and Time & BSpecificP & GeneralP & $\begin{array}{l}\text { Total } \\
\text { \# BSP }\end{array}$ & $\begin{array}{l}\text { Bin } \\
\text { IOA \% }\end{array}$ & $\begin{array}{l}\text { Total } \\
\text { \# GP }\end{array}$ & $\begin{array}{l}\text { Bin } \\
\text { IOA \% }\end{array}$ \\
\hline \multicolumn{7}{|l|}{ Bin $1(: 00-: 29)$} \\
\hline \multicolumn{7}{|l|}{ Bin $2(30-59)$} \\
\hline \multicolumn{7}{|l|}{ Bin 3 (1:00-1:29) } \\
\hline \multicolumn{7}{|l|}{ Bin $4(1: 30-1: 59)$} \\
\hline \multicolumn{7}{|l|}{ Bin $5(2: 00-2: 29)$} \\
\hline \multicolumn{7}{|l|}{ Bin 6 (2:30-2:59) } \\
\hline \multicolumn{7}{|l|}{ Bin $7(3: 00-3: 29)$} \\
\hline \multicolumn{7}{|l|}{ Bin $8(3: 30-3: 59)$} \\
\hline \multicolumn{7}{|l|}{ Bin $9(4: 00-4: 29)$} \\
\hline \multicolumn{7}{|c|}{ Use Self-monitoring? Yes / No } \\
\hline \multicolumn{7}{|c|}{ Use Self-monitoring? Yes / No } \\
\hline Bin \# and Time & BSpecificP & GeneralP & $\begin{array}{c}\text { Total } \\
\text { \# BSP } \\
\end{array}$ & $\begin{array}{l}\text { Bin } \\
\text { IOA \% }\end{array}$ & $\begin{array}{l}\text { Total } \\
\text { \# GP } \\
\end{array}$ & $\begin{array}{l}\text { Bin } \\
\text { IOA \% }\end{array}$ \\
\hline \multicolumn{7}{|l|}{ Bin $1(: 00-: 29)$} \\
\hline \multicolumn{7}{|l|}{ Bin $2(30-59)$} \\
\hline \multicolumn{7}{|l|}{ Bin 3 (1:00-1:29) } \\
\hline \multicolumn{7}{|l|}{ Bin 4 (1:30-1:59) } \\
\hline \multicolumn{7}{|l|}{ Bin 5 (2:00-2:29) } \\
\hline \multicolumn{7}{|l|}{ Bin 6 (2:30-2:59) } \\
\hline Bin 7 (3:00-3:29) & & & & & & \\
\hline Bin 8 (3:30-3:59) & & & & & & \\
\hline Bin $9(4: 00-4: 29)$ & & & & & & \\
\hline Bin $10(4: 30-4: 59)$ & & & & & & \\
\hline & & & & e Self-mo & itoring? & Yes / No \\
\hline
\end{tabular}




\section{Appendix B}

\section{Study Observation and Study IOA Protocol}

\section{Items Needed:}

1. Pen or pencil

2. BSP Data Collection Sheet

3. Timer or watch/clock

\section{Prior to each session:}

1. Observers with necessary items will position themselves so they have a direct line of vision to the teacher being observed. Observers should be situated close enough to hear teacher-student interactions.

2. Observers will angle themselves such that neither can see the other's data collection sheet.

3. Once situated, observers will count down 3,2,1, start, and start a 5-minute timer. This will be used to guide when each observer will move into the next 30 -second bin.

\section{During each session:}

1. Observers will put a tally mark in the respective 30-s time bin for each instance of BSP or GP, respectively.

2. Observers may move if needed, but must keep their observation sheets out of sight from each other.

\section{Following each session:}

1. Observers will compare tallies per bin for BSP and GP and discuss possible reasons for discrepant tally totals across the session.

2. One or both observers will then calculate an Interobserver Agreement score by using the following formula to create a "mean count per interval IOA \%":

\# of tallies in Bin 1 for observer 1_+ \# of tallies in Bin $\mathrm{n}$ for Obs $1 \ldots$ \# of tallies in Bin 1 for observer 2 \# of tallies in Bin $n$ for Obs 2 \# of $n$ total bins

This ratio will then be multiplied by 100 to provide the mean count per interval IOA \%.

3. Observers will then record their IOA on the IOA Tracking Sheet.

\section{Reliability Criteria:}

Observers will be considered reliable when they have reached and maintained $85 \%$ IOA for both BSP and GP across 3 consecutive sessions while observing two different teachers. 
INSTRUCTIONAL PACKAGE TO PROMOTE BEHAVIOR-SPECIFIC PRAISE 70

\section{Appendix C IOA Tracking Sheet}

Reliability Criteria:

Observers will be considered reliable when they have reached and maintained 85\% IOA for both BSP and GP across 3 consecutive sessions while observing the same teacher.

Observers will be considered generally reliable when they have reached and maintained $85 \%$ IOA for both BSP and GP across 3 consecutive sessions while observing two different teachers.

\begin{tabular}{|c|c|c|c|c|c|c|}
\hline $\begin{array}{r}\text { SSN } \\
\#\end{array}$ & Observer Initials & Date & $\begin{array}{l}\text { Teacher's } \\
\text { De-identified } \\
\text { Number: }\end{array}$ & BSP IOA & $\begin{array}{l}\text { General } \\
\text { Praise IOA }\end{array}$ & $\begin{array}{c}\text { Reliable? } \\
\text { Y/YY/N }\end{array}$ \\
\hline 1 & & & & & & \\
\hline 2 & & & & & & \\
\hline 3 & & & & & & \\
\hline 4 & & & & & & \\
\hline 5 & & & & & & \\
\hline 6 & & & & & & \\
\hline 7 & & & & & & \\
\hline 8 & & & & & & \\
\hline 9 & & & & & & \\
\hline 10 & & & & & & \\
\hline 11 & & & & & & \\
\hline 12 & & & & & & \\
\hline 13 & & & & & & \\
\hline 14 & & & & & & \\
\hline 15 & & & & & & \\
\hline 16 & & & & & & \\
\hline 17 & & & & & & \\
\hline 18 & & & & & & \\
\hline 19 & & & & & & \\
\hline 20 & & & & & & \\
\hline 21 & & & & & & \\
\hline 22 & & & & & & \\
\hline 23 & & & & & & \\
\hline 24 & & & & & & \\
\hline 25 & & & & & & \\
\hline 26 & & & & & & \\
\hline 27 & & & & & & \\
\hline 28 & & & & & & \\
\hline 29 & & & & & & \\
\hline 30 & & & & & & \\
\hline 31 & & & & & & \\
\hline 32 & & & & & & \\
\hline 33 & & & & & & \\
\hline 34 & & & & & & \\
\hline
\end{tabular}


Appendix D

Post-Presentation Survey

\section{Demographics:}

Age (Years):

Gender:

Degree or Major:

Ethnicity:

I am a (Circle One):

Freshman Sophomore Junior Senior

Please answer the questions below while thinking about the presentation you just watched. For each item, please use the following scale:

1 - Strongly Disagree

2 - Somewhat Disagree

3 - Neutral (Neither Agree nor Disagree)

4 - Somewhat Agree

5 - Strongly Agree

How much do you agree with the following statements?

1. The presentation made it easy to understand what behavior-specific praise is:

2. I am going to use behavior-specific praise more often while I teach:

3. I know the difference between general praise and behavior-specific praise:

4. The presentation was interesting:

5. The presentation was boring:

6. The presentation was important for me to watch because of its content:

7. I would recommend the presentation to other preschool teachers :

8. Before I watched the presentation, I didn't know much about behavior specific praise:

9. The presentation helped me to understand what behavior-specific praise is:

10. The presentation helped me learn how to use behavior-specific praise:

11. The presentation helped me learn how to self-monitor my use of behavior-specific praise while I teach:

12. Overall, I was satisfied with the presentation:

Thank You! 
INSTRUCTIONAL PACKAGE TO PROMOTE BEHAVIOR-SPECIFIC PRAISE 72

\author{
Appendix E \\ Post-Study Survey, Pre-Interviews
}

\title{
Instructions:
}

Please indicate how much you agree or disagree with each of the items below. For each item, use the following key:

1 - Strongly Disagree

2 - Somewhat Disagree

3 - Neutral (Neither Agree nor Disagree)

4 - Somewhat Agree

5 - Strongly Agree

\section{Ease of Implementation:}

1. I liked using behavior-specific praise:

2. I liked using self-monitoring:

3. It was easy for me to use behavior-specific praise:

4. It was easy for me to use self-monitoring:

5. I think using behavior-specific praise was worth the effort:

6. I think using self-monitoring was worth the effort:

7. I experienced discomfort when trying to use self-monitoring:

\section{Endorsement of Intervention:}

1. I am willing to use behavior-specific praise with my future students:

2. I am willing to use self-monitoring in future teaching settings:

3. I think other preschool teachers would want to use behavior-specific praise:

4. I think other preschool teachers would want to use self-monitoring:

5. I would recommend other preschool teachers use behavior-specific praise:

6. I would recommend other preschool teachers use self-monitoring: 
INSTRUCTIONAL PACKAGE TO PROMOTE BEHAVIOR-SPECIFIC PRAISE 73

\section{Appendix E (Continued)}

\section{Effects of the Intervention}

1. I think there are disadvantages to using behavior-specific praise:

2. I think there are disadvantages to using self-monitoring:

3. I think the children I work with experienced discomfort when I used behavior-specific praise:

4. I think the children I work with experienced discomfort when I used self-monitoring:

5. I think there are undesirable effects on my own teaching when I use behavior-specific praise:

6. I think there are undesirable effects on my children's development when I use behavior-specific praise:

7. I think there are undesirable effects on my own teaching when I use self-monitoring:

8. I think behavior-specific praise has left a long-lasting positive impact on my children's development:

9. I think self-monitoring has left a long-lasting positive impact on my teaching:

\section{Understanding of Intervention Components:}

1. I understand how to use self-monitoring:

2. I understand why I should use self-monitoring:

3. I understand how to use behavior-specific praise:

4. I understand why I should use behavior-specific praise:

May we contact you for a brief follow-up interview? If yes, please enter your contact info here: Name:

Email:

Thank you! 
INSTRUCTIONAL PACKAGE TO PROMOTE BEHAVIOR-SPECIFIC PRAISE 74

\section{Appendix F \\ Follow-Up Interview Schedule}

Q1: What was your overall experience of the training presentation on behavior specific praise and selfmonitoring?

Follow-up Q's include:

a. Was it useful why or why not?

b. Was it easy to understand why or why not?

c. Would you recommend its use to other preschool centers why or why not?

Q2: Were there any questions you wanted to ask about BSP or self-monitoring after you watched the training presentation?

Follow-up Q's include:

a. Was anything unclear, what was it?

Q3: Were there any barriers to your using BSP after you watched the presentation?

Follow-up Q's include:

a. Was it easy for you to find target behaviors to praise?

b. Were you unsure about when a behavior should be praised or when it shouldn't?

c. What could help you use BSP more often?

Q4: Were there any barriers to your using the golf clicker to help you self-monitor?

Follow-up Q's include:

a. Was the golf clicker easy to use?

b. How often throughout the day were you using the golf clicker?

c. Were you using it every day?

d. Did you ever record your total count of BSPs at the end of the day?

e. What could help you use the golf clicker more often? 
INSTRUCTIONAL PACKAGE TO PROMOTE BEHAVIOR-SPECIFIC PRAISE 75

Appendix G

Behavior Specific Praise Workshop Checklist

Your Name:

Please make a checkbox after you have completed each of the following tasks, and return this sheet to your Director:

$\square \quad$ Received golf counter from Director

Viewed and listened to the online workshop

Completed survey rating the online workshop 
INSTRUCTIONAL PACKAGE TO PROMOTE BEHAVIOR-SPECIFIC PRAISE 76

Appendix H

Session Tracking Sheet

\begin{tabular}{|c|c|c|c|c|c|c|c|c|}
\hline $\begin{array}{r}\text { SSN } \\
\#\end{array}$ & $\begin{array}{l}\text { Observer } \\
\text { Initials }\end{array}$ & Date & $\begin{array}{l}\text { Teacher's } \\
\text { De- } \\
\text { identified } \\
\text { Number: }\end{array}$ & $\begin{array}{l}\text { BSP } \\
\text { Total }\end{array}$ & $\begin{array}{l}\text { GP } \\
\text { Total }\end{array}$ & $\begin{array}{l}\text { BSP } \\
\text { IOA }\end{array}$ & $\begin{array}{l}\text { General } \\
\text { Praise } \\
\text { IOA }\end{array}$ & $\begin{array}{l}\text { Use Self- } \\
\text { Monitor? }\end{array}$ \\
\hline 1 & & & & & & & & \\
\hline 2 & & & & & & & & \\
\hline 3 & & & & & & & & \\
\hline 4 & & & & & & & & \\
\hline 5 & & & & & & & & \\
\hline 6 & & & & & & & & \\
\hline 7 & & & & & & & & \\
\hline 8 & & & & & & & & \\
\hline 9 & & & & & & & & \\
\hline 10 & & & & & & & & \\
\hline 11 & & & & & & & & \\
\hline 12 & & & & & & & & \\
\hline 13 & & & & & & & & \\
\hline 14 & & & & & & & & \\
\hline 15 & & & & & & & & \\
\hline 16 & & & & & & & & \\
\hline 17 & & & & & & & & \\
\hline 18 & & & & & & & & \\
\hline 19 & & & & & & & & \\
\hline 20 & & & & & & & & \\
\hline 21 & & & & & & & & \\
\hline 22 & & & & & & & & \\
\hline 23 & & & & & & & & \\
\hline 24 & & & & & & & & \\
\hline 25 & & & & & & & & \\
\hline 26 & & & & & & & & \\
\hline 27 & & & & & & & & \\
\hline 28 & & & & & & & & \\
\hline 29 & & & & & & & & \\
\hline 30 & & & & & & & & \\
\hline 31 & & & & & & & & \\
\hline 32 & & & & & & & & \\
\hline 33 & & & & & & & & \\
\hline 34 & & & & & & & & \\
\hline 35 & & & & & & & & \\
\hline 36 & & & & & & & & \\
\hline 37 & & & & & & & & \\
\hline 38 & & & & & & & & \\
\hline 39 & & & & & & & & \\
\hline 40 & & & & & & & & \\
\hline
\end{tabular}


INSTRUCTIONAL PACKAGE TO PROMOTE BEHAVIOR-SPECIFIC PRAISE 77

\section{Appendix I}

\section{Director's Handbook for Video-Based Professional Development}

\section{Topics Included:}

Behavior-Specific Praise

$\&$

Self-monitoring 
INSTRUCTIONAL PACKAGE TO PROMOTE BEHAVIOR-SPECIFIC PRAISE 78

\section{Appendix I Continued}

\section{Table of Contents}

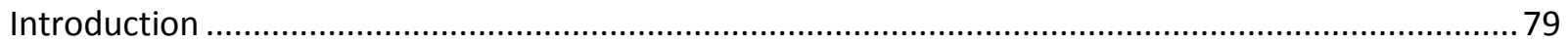

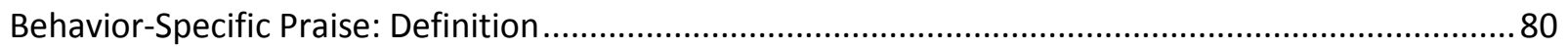

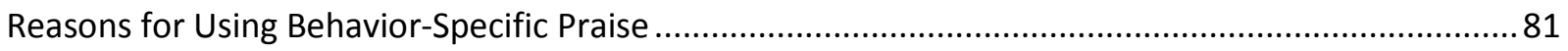

Instructions for Using the Video-Based Professional Development ................................................... 82

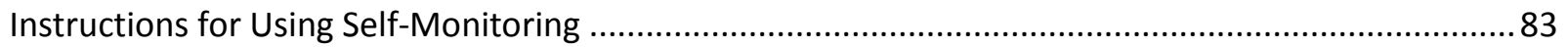

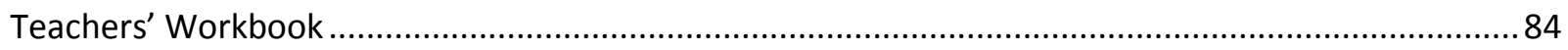

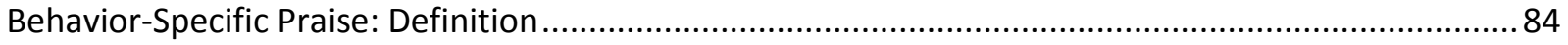

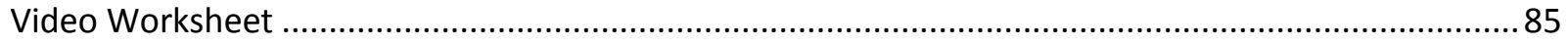

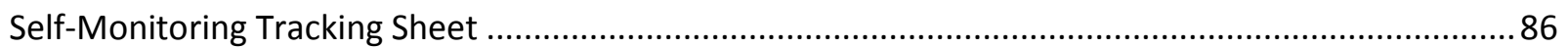


INSTRUCTIONAL PACKAGE TO PROMOTE BEHAVIOR-SPECIFIC PRAISE 79

\section{Appendix I Continued}

\section{Introduction}

This Director's Handbook will help guide you through the use of the video-based professional development for increasing behavior-specific praise in your classroom. This video was developed with every preschool teacher in mind, and we hope you and your staff find it informative and helpful to improving daily interactions between teachers and children.

This handbook contains:

1. Definitions of Behavior-Specific Praise, with some examples that can be modified to fit any situation

2. Reasons for using Behavior-Specific Praise more frequently

3. Instructions for how to use the video-based professional development as a teaching guide

4. Instructions for how teachers can use self-monitoring

5. Teachers' workbook

6. Teachers' self-monitoring tracking sheets and graph template 
INSTRUCTIONAL PACKAGE TO PROMOTE BEHAVIOR-SPECIFIC PRAISE 80

\section{Appendix I Continued \\ Behavior-Specific Praise: Definition}

There are three components of behavior-specific praise:

It is a statement that is:

1. Positive

2. Describes the good behavior

3. Is given immediately after or during the good behavior

Behavior-specific praise is any positive statement that also describes the appropriate or desired behavior, immediately after or during the good behavior.

Here are some common examples:

- "I love the way you are cleaning up!"

- "Thank you for washing your hands!"

- "Great job writing your letters!"

- "Super! You worked really hard on your picture!"

- "I'm so impressed at how quietly you're working right now!"

- "Way to go, you are sharing like a good friend!" 


\section{INSTRUCTIONAL PACKAGE TO PROMOTE BEHAVIOR-SPECIFIC PRAISE 81}

\section{Appendix I Continued}

\section{Reasons for Using Behavior-Specific Praise}

High quality early education has been shown to have broad positive effects on short- and long-term development. Some short-term benefits of high quality early education include higher academic performance, better social skills, fewer grade retentions, and fewer referrals for special education services. The best way to improve the quality of early education environments is through using evidence-based practices, because these practices have been shown to contribute to immediate and long-term benefits for students and teachers.

Behavior-Specific Praise is one of the most well-researched evidence-based practices an early educator can use. It can be used to increase desired behaviors, teach new skills, reduce problem behavior, and create a nurturing environment that helps children develop trusting relationships with caregivers. In addition, there has been no evidence that using behavior-specific praise has negative side effects. Behavior-specific praise has actually been shown to increase children's intrinsic motivation to learn and participate in the classroom.

\section{References:}

1. Barnett, W. S. (2008). Preschool education and its lasting effects: Research and policy implications. Boulder and Tempe: Education and the Public Interest Center \& Education Policy Research Unit. Retrieved from: http://epicpolicy.org/pbulications/preschool-education

2. Cameron, J., Banko, K. M., \& Pierce, W. D. (2001). Pervasive negative effects of rewards on intrinsic motivation: The myth continues. The Behavior Analyst, 24(1), 1-44.

3. Deci, E. L., Koestner, R., \& Ryan, R. M. (1999). A meta-analytic review of experiments examining the effects of extrinsic rewards on intrinsic motivation. Psychological Bulletin, 125(6), 627-668.

4. Isaacs, J. B. (2008). Impacts of early childhood programs. Retrieved from Brookings Institute Website: https://www.brookings.edu/wpcontent/uploads/2016/06/09_early_programs_isaacs.pdf

5. Jennings, J. L., \& Diprete, T. A. (2010). Teacher effects on social and behavioral skills in early elementary school. Sociology of Education, 83(2), 135-159. doi: 10.1177/0038040710368011 


\section{INSTRUCTIONAL PACKAGE TO PROMOTE BEHAVIOR-SPECIFIC PRAISE 82}

\section{Appendix I Continued}

\section{Instructions for Using the Video-Based Professional Development}

The video on Behavior-Specific Praise should be used with this handbook. To get the best out of the video, have your teachers watch it in small groups or individually, whichever works best for your center. The video should be watched enough times to help you and your teachers know what Behavior-Specific Praise is, how to use it, and how to use the self-monitoring strategy recommended here. Other teachers who have done this have said that using the counter to self-monitor was easy and they recommended its use in other preschools.

1. Tell your teachers about this program, that its goal is to improve learning, reduce problem behavior, and reduce stress in the classroom.

2. Print out the teacher's handbook (pp. 8-11 below) and provide it to them.

3. Consider creating a binder to hold all of your teachers' self-monitoring tracking sheets (p. 10) and graphs (p. 11)

4. Ask your teachers to watch the video independently or in small groups

5. Provide them access to hand-held counters

6. Encourage them to use the strategies in the video, including self-monitoring, and determine an easy way for you to check in on how their progress is going

a. Progress check-ins can happen as often as you see fit. Your role as the Director or Lead Teacher should be supportive. You want to help the teachers in the classroom create a nurturing, lowerstress learning environment in which children can thrive. The progress check-ins should be used to trouble shoot difficulties, and for you to provide praise to the teachers when they reach their goals.

b. Consider meeting individually with the teachers to review their daily numbers and graphs. These check-in meetings can be added to regularly scheduled staff meetings.

c. Small group meetings can also be useful as progress check-ins, but be sure that you avoid embarrassing teachers who don't reach their goals. Remember to help them problem solve.

d. Progress check-ins can happen daily, every other day, or weekly. This is ultimately up to you and your teachers' schedules.

7. Encourage teachers to watch the video multiple times if they think they need or want to. The video should be used as a reference to guide teaching practices, just like this handbook and the teachers' workbooks. 
INSTRUCTIONAL PACKAGE TO PROMOTE BEHAVIOR-SPECIFIC PRAISE 83

\section{Appendix I Continued}

\section{Instructions for Using Self-Monitoring}

We highly recommend you use hand-held counters for your teachers to self-monitor. They are extremely affordable (less than $\$ 6$ each online), and very easy to use.

Hand-held counters should be kept in a consistent place when they are not in use. Find a basket, a drawer, a shelf, or a cubby that they could be left in. Remind teachers before they begin their daily activity, that they should use the hand monitors to track their own use of behavior-specific praise.

Before each self-monitoring activity, teachers should zero the counter by twisting the knob on the side until all the numbers reach "0000". At the end of the activity, the teachers should write down the number displayed on their counter on their tracking sheet (see $\mathrm{p} 10$ below), and when they have time, they should add this number to their graph (see $\mathrm{p} 11$ below).

The counters should be returned to their storage place sometime soon after the self-monitoring activity is over to help avoid losing them. 
INSTRUCTIONAL PACKAGE TO PROMOTE BEHAVIOR-SPECIFIC PRAISE 84

\section{Appendix I Continued}

Teachers' Workbook

(Keep these sheets together in your data binder after you have finished them)

Behavior Specific Praise Workshop Checklist

Your Name:

Please make a checkbox after you have completed each of the following tasks, and return this sheet to your Director:

\section{Received golf counter from Director}

Viewed and listened to the online workshop

Completed survey rating the online workshop

\section{Behavior-Specific Praise: Definition}

There are three components of behavior-specific praise:

It is a statement that is:

1. Positive

2. Describes the good behavior

3. Is given immediately after or during the good behavior

Behavior-specific praise is any positive statement that also describes the appropriate or desired behavior, immediately after or during the good behavior.

Here are some common examples:

- "I love the way you are cleaning up!"

- "Thank you for washing your hands!"

- "Great job writing your letters!"

- "Super! You worked really hard on your picture!"

- "I'm so impressed at how quietly you're working right now!"

- "Way to go, you are sharing like a good friend!"

\section{Appendix I Continued}


INSTRUCTIONAL PACKAGE TO PROMOTE BEHAVIOR-SPECIFIC PRAISE 85

\section{Video Worksheet}

Behavior-specific praise statement \#1:

Student's name:

What you want them to do:

What you would say when they do it (remember to include a praise statement and a description of what they did):

BSP\#1 (write your statement on the line below):

Behavior-specific praise statement \#2 (optional):

Behavior-specific praise statement \#3 (optional):

Behavior-specific praise statement \#4 (optional):

Behavior-specific praise statement \#5 (optional):

Behavior-specific praise statement \#6 (optional): 


\section{Appendix I Continued}

\section{Self-Monitoring Tracking Sheet}

Teacher's Name:

Activity:
\begin{tabular}{|l|l|l|l|l|l|l|l|l|l|l|l|}
\hline Date & & & & & & & & & & & \\
\hline $\begin{array}{l}\text { Number of } \\
\text { BSPs Given: }\end{array}$ & & & & & & & & & & & \\
\hline
\end{tabular}

Teacher's Name:

Activity:

Goal:

(\# of minutes of Activity; ex: directed reading for 15 minutes, goal = 15 BSP for that activity)

\begin{tabular}{|l|l|l|l|l|l|l|l|l|l|l|l|}
\hline Date & & & & & & & & & & & \\
\hline $\begin{array}{l}\text { Number of } \\
\text { BSPs Given: }\end{array}$ & & & & & & & & & & & \\
\hline
\end{tabular}

Teacher's Name:

Activity: Goal: (\# of minutes of Activity; ex: directed reading for 15 minutes, goal = 15 BSP for that activity)

\begin{tabular}{|l|l|l|l|l|l|l|l|l|l|l|l|}
\hline Date & & & & & & & & & & & \\
\hline $\begin{array}{l}\text { Number of } \\
\text { BSPs Given: }\end{array}$ & & & & & & & & & & & \\
\hline
\end{tabular}

